\title{
Modelling Investigation of the Thermal Treatment of Ash-Contaminated Particulate Filters
}

\author{
Chung Ting Lao ${ }^{1}$ Jethro Akroyd ${ }^{1,2} \cdot$ Alastair Smith $^{3} \cdot$ Neal Morgan $^{3} \cdot$ Kok Foong Lee $^{4} \cdot$ Daniel Nurkowski $^{4}$. \\ Markus Kraft ${ }^{1,2,5}$
}

Received: 28 September 2020 / Revised: 25 January 2021 / Accepted: 10 February 2021 / Published online: 18 September 2021

(C) The Author(s) 2021

\begin{abstract}
This paper investigates the impact of thermal treatment on the pressure drop of particulate filters containing ash deposits. A one-dimensional model has been developed and applied to describe the deposition of soot and ash particles, and estimate the spatial distribution of the deposits in such filters. Phenomenological models have been developed to describe the potential sintering and cracking of the ash deposits caused by thermal treatment of the filter. The model results are in good agreement with experimental measurements of the reduction in the pressure drop in thermally treated filters. It was found that crack formation in the ash layer can lead to significant reduction of the pressure drop at relatively low temperatures. Sintering of ash deposits in the wall and the ash plug also contributes towards a decrease in filter pressure drop at higher temperatures. This work is the first attempt to model the impact of the thermal treatment of ash in particulate filters in order to support the development of future ash management strategies. The cracking of the ash layer during the thermal treatment has been identified to be the most critical effect for pressure drop reduction.
\end{abstract}

Keywords Ash $\cdot$ Particulate filter $\cdot$ Pressure drop $\cdot$ Emissions $\cdot$ Cracking $\cdot$ Sintering $\cdot$ Thermal treatment

\section{Introduction}

Internal combustion engines (ICEs) are a major source for particulate matter (PM) emissions [1]. Particulate matter is known to have an adverse impact on public health [2] and the environment [3]. Governing bodies around the world have been imposing increasingly stringent emission

Markus Kraft

mk306@cam.ac.uk

1 Department of Chemical Engineering and Biotechnology, University of Cambridge, Philippa Fawcett Drive, Cambridge, CB3 0AS, UK

2 Cambridge Centre for Advanced Research and Education in Singapore, 1 Create Way, CREATE Tower, \# 05-05, Singapore, 138602, Singapore

3 Shell Centre, York Road, London, SE1 7NA, UK

4 CMCL Innovations, Sheraton House, Cambridge, CB3 0AX, UK

5 School of Chemical and Biomedical Engineering, Nanyang Technological University, 62 Nanyang Drive, Singapore, 637459, Singapore standards and more rigorous testing protocols to reduce pollution [4-7] from ICEs. Diesel particulate filters (DPFs) have been widely adopted for diesel-fuelled engines in order to comply with these emission standards [8]. Recently, the introduction of regulations governing particle number (PN) emissions has also driven the introduction of gasoline particulate filters (GPFs) on gasoline direct injection (GDI) vehicles [9-11].

The typical operating cycle of a particulate filter involves the collection of solid particles, followed by an active regeneration process that reduces the pressure drop of the filter by burning off the trapped particles. The typical behaviour of a particulate filter during the filtration process is shown in Fig. 1. Particles are initially trapped in the porous walls of the filter by deep-bed filtration, leading to a rapid increase in the pressure drop and an increase in the filtration efficiency of the filter. As the pore openings in the filter wall are partially blocked, particles can no longer penetrate the walls and a soot cake layer is formed on the surface of the walls. The pressure drop increases at a lower rate during the cake formation stage. Active regeneration is triggered when the filter pressure drop reaches a preset threshold. If the filter is coated with oxidation catalyst, 
Fig. 1 Typical behaviour of ash-free and ash-loaded filters during soot filtration. Deep-bed filtration via soot deposition inside the porous walls of the filter leads to a rapid increase in the pressure drop at low soot loading in the ash-free filter. Ash deposits in the ash-loaded filter lead to an increase in the pressure drop compared to the unloaded filter, but prevent deep-bed filtration of the soot in resulting a lower pressure drop compared to the ash-free filter at high soot loading

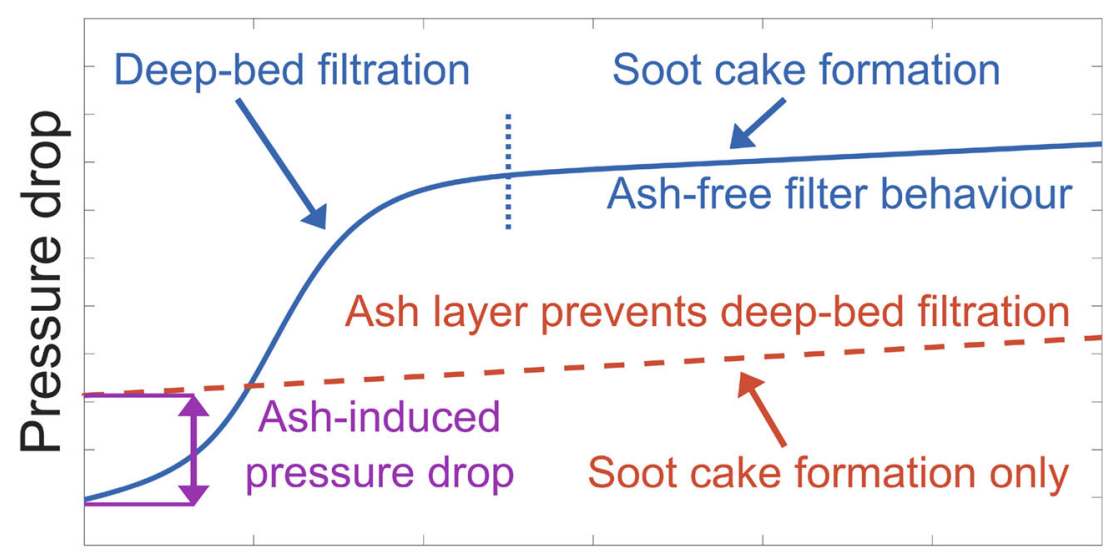

Soot load passive regeneration which continuously oxidise trapped carbonaceous particles can also occur under appropriate operating conditions.

In addition to soot, the particulate emissions from ICEs contain metallic ash originating from lubrication oil, fuel additives, engine wear, corrosion and abrasion [12-15]. Unlike soot, the metallic ash is incombustible, such that it accumulates over the lifetime of the filter [16]. Ash can deposit within the filter wall, as a particulate layer and as a plug at the end of filter channels [15]. The distribution of ash deposits is closely related to the regeneration strategy, but all forms of ash deposits can be found in actively regenerated and passively regenerated filters [17]. Whilst metallic ash makes up only a small amount of diesel PM [18, 19], PM emitted by GDI engines can have much higher ash-to-soot ratio [20], with studies showing numbers in the range of $20-50 \%$ by mass [21]. This is because GDI engines emit less soot than diesel engines due to longer ignition delay and higher volatility of gasoline fuel [22]. Whilst the accumulation of the ash contributes to the pressure drop [23], the presence of an ash layer on the filter walls can lead to improved filtration efficiency. The ash layer can eliminate the deep-bed stage of the filtration and, in so doing, can reduce the pressure drop over the filter at high soot loadings [24] (see Fig. 1). This is especially beneficial for GPFs, where soot cake formation is harder to sustain [25]. On the other hand, ash deposits reduce the available storage capacity, necessitating an increase in the frequency of regeneration events and incurring an associated fuel penalty [26]. Ash deposits can also lead to an increase in the maximum filter temperature during regeneration [27] which can damage the filter and limits its service lifetime [28]. In addition, the ash layer can negatively impact the effectiveness of passive regeneration by acting as a diffusion barrier between catalytic washcoat and the soot cake layer [29].
Many technologies have been considered to minimise the negative impact of ash accumulation and extend the service lifetime of particulate filters. The use of lubricants with minimal inorganic additives ("ashless oil") can mitigate the production of lubricant-derived ash [30]. However, the contribution of corrosion and wear can still be significant, where it has been found that up to $50 \%$ of ash deposits in GPFs could come from corrosion of the moving parts in an engine and from eroded upstream catalysts [31]. Some progress has been made using alternative filter geometries. Asymmetric Channel Technology (ACT) has been shown to improve the ash storage capacity of particulate filters by having larger inlet channels than outlet channels [32]. Alternatives to square channel cross-section designs have also been shown to reduce ash-induced pressure drop e.g. hexagonal and octo-square geometries [33]. The engine system operation may also be optimised to minimise the impact of ash deposits by modifying the distribution and properties of the ash within a filter [15].

The deposition of ash in particulate filters has been studied by Sappok et al. [34-37] using an accelerated ash loading system. Sappok et al. [36] observed that the pressure drop of ash-contaminated filters decreased after exposure to high temperatures. Analysis of the filters showed a reduction in the bulk volume of ash deposits due to sintering and crack formation in the ash layer. This indicates the potential of thermal treatment as a viable ash management strategy [15]. However, the relative contributions of the cracking and sintering are unexplored.

The purpose of the paper is to study the impact of thermal treatment on ash deposits in particulate filters using a computational model. Modelling allows the exploration of scenarios that are difficult to investigate using experiments. The development of the model provides helps quantify the effects of the thermal treatment process and provides insights that can aid the optimisation of ash management 
Fig. 2 Spatial representations of a Wall Flow Monolith (WFM). When ash deposits exist in the WFM, additional volume elements are introduced to describe the ash layer. The implicit reduction of the inlet channel volume due to the ash layer and ash plug formation is considered by the model

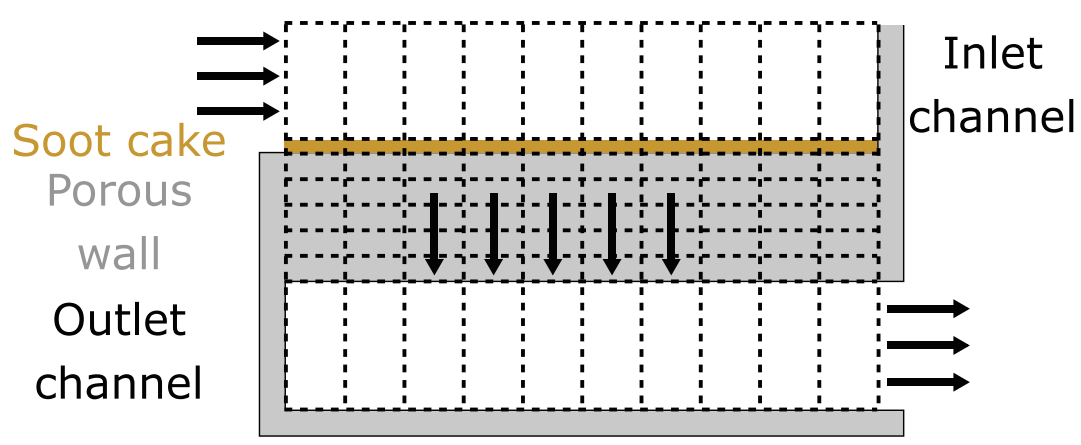

(a) Spatial discretisation of a Wall Flow Monolith (WFM) without ash deposits in the model.



(b) Spatial discretisation of a Wall Flow Monolith (WFM) with ash deposits in the model. strategies. In this work we aim to investigate the relative importance of sintering and cracking on the reduction of the ash-induced pressure drop in a particulate filter.

The rest of the paper is structured as follows: The model is described in Section 2. The model is calibrated and assessed against the experimental data reported by Sappok et al. [34-36] in Section 3.2. The model for thermally treated ash deposits is applied in Section 3.3. Suggestions for future development are discussed in Section 3.4.

\section{Model Description}

The model used in this work considers a pair of inlet and outlet channels in a Wall Flow Monolith (WFM) - a common design for particulate filters. Aspects of the model have been described previously, where it was used to consider soot filtration [38, 39]. The spatial representation of the model is shown in Fig. 2(a). The channels are discretised in the axial and through-wall directions, resolving gradients along the channels and through the walls, but neglecting any variation across the soot cake. Particles are introduced into the filter via exhaust flowing into the inlet channel. The particles are then either filtered by the porous wall or exit the filter with the gas flow through the outlet channel.
In this work, the model is extended to consider ash deposition. The spatial representation of the extended model is shown in Fig. 2(b). The presence of the ash layer is explicitly considered in the model. The ash layer is formed from incombustible residues that are left behind when the soot cake is burned off during regeneration of the filter. The ash layer is expected to be in contact with the porous wall, with a new soot cake eventually forming on top of the ash layer. The ash plug is assumed to be impervious to gas flow, and is outside the spatial domain considered by the model, but is implicitly considered in the model in the sense that it reduces the length of the inlet channel.

\subsection{Governing Equations}

The engine exhaust first flows into the inlet channels of the WFM. Since the inlet channels are closed-ended, the exhaust is forced to flow through the soot and ash layers (should they exist) and the porous wall. The exhaust then exits the WFM via the outlet channel. The model permits gas flow in two directions: in the axial direction along the inlet and outlet channels, and through the porous media including the soot cake, the ash layer and the filter wall in the through-wall direction. These two flows are perpendicular [40]. 
Fig. 3 Illustration of the primary particle diameter $d_{\text {pri }}$, the mobility diameter $d_{\text {mob }}$ and the fractal diameter $d_{\text {frac }}$ of a typical aggregate considered by the particle model

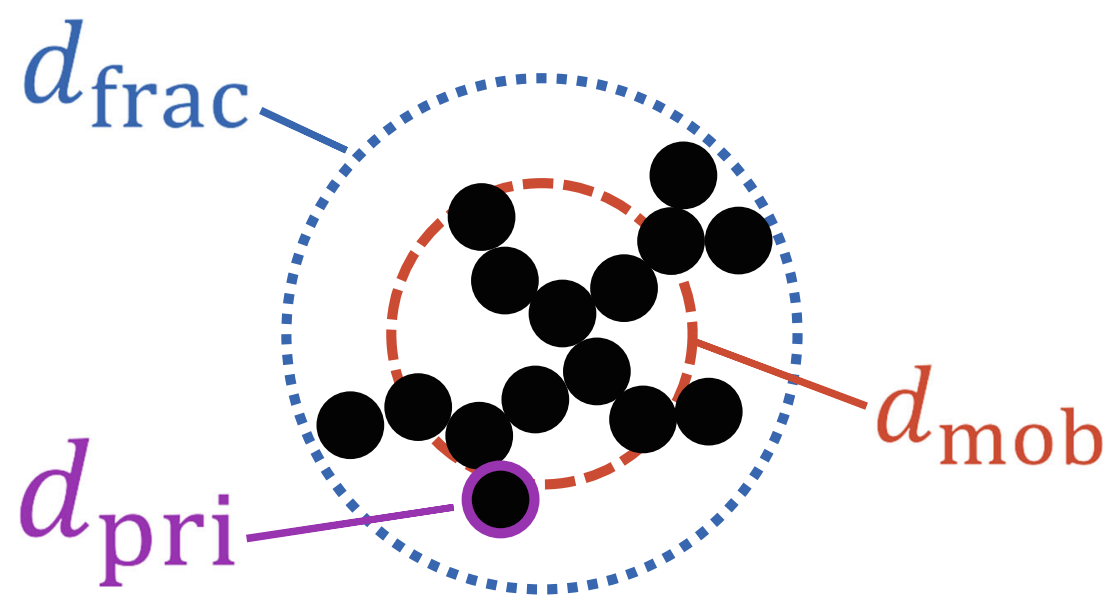

The gas flow in the inlet and outlet channels is governed by the Bernoulli equation

$P_{i-1}+\frac{1}{2} \rho_{i-1} u_{i-1}^{2}=P_{i}+\frac{1}{2} \rho_{i} u_{i}^{2}+\frac{F \mu L_{i}}{D^{2}} u_{i}, \quad i \in \begin{cases}S_{\mathrm{ci}} & \text { inlet channel } \\ S_{\mathrm{co}} & \text { outlet channel }\end{cases}$

where $P$ is the pressure, $\rho$ is the mass density of the gas, $u$ is the gas velocity along the channel, $F$ is a friction factor $(F=28.454$ for a square channel [41]), $\mu$ is the dynamic viscosity of the gas, $L$ is the distance between neighbouring volume elements and $D$ is the side length of the cross-section of a square channel (i.e. the hydraulic diameter). Subscript $i$ indexes the volume elements of the channels and increments in the axial direction. Equation (1) applies to both inlet and outlet channels, wherePressure Drop During Soot Filtration Loading the index sets $S_{\mathrm{ci}}$ and $S_{\text {co }}$ reference the volume elements in the inlet and outlet channels respectively. Equation (1) is solved to obtain $P$ and $u$. The parameters $F, L$ and $D$ are provided as inputs based on the geometry of the particulate filter. The ideal gas law is used to calculate $\rho$ from the thermodynamic state of the gas phase. The dynamic viscosity of the gas mixture is assumed to be that of air.

The pressure and the gas flow from the inlet channel, through the porous media and into the outlet channel is governed by Darcy's law

$P_{j}-P_{j+1}=\frac{\mu v_{j} L_{j}}{\kappa_{j}}, \quad j \in S_{\mathrm{ci}} \cup S_{\mathrm{pm}} \cup S_{\mathrm{co}}$

where $v$ and $\kappa$ are the gas flow velocity in the through-wall direction and the permeability across the porous medium. Subscript $j$ indexes the volume elements in the throughwall direction. The index sets $S_{\mathrm{ci}}, S_{\mathrm{pm}}$ and $S_{\mathrm{co}}$ reference the volume elements in the inlet channel, the porous media, including the soot cake layer, the ash layer and the filter wall, and the outlet channel respectively. Equation (2) is solved to obtain $P$ and $v$. The treatments of $L$ and $\mu$ are identical to Eq. (1). The permeability of porous medium $\kappa$ is provided by the filtration model (see Section 2.2).

The temperature of the system is assumed to be constant and chemical reactions are neglected in the simulations in this work, such that the thermal energy balance and species equations are omitted.

Previous applications of the model $[38,39]$ assumed all particles to be spherical and purely carbonaceous. These assumptions are relaxed in this work. Figure 3 illustrates a typical aggregate considered by the particle model used in this work. Particle diameters relevant to this work are shown in Fig. 3. The particle model considered aggregated composed of spherical primary particles that are equally sized. The primary particle diameter is denoted as $d_{\text {pri }}$. The mobility diameter of the aggregate $d_{\mathrm{mob}}$ is the diameter of a spherical particle that has the same aerodynamic drag coefficient as the aggregate [42]. The fractal diameter $d_{\text {frac }}$ is the diameter of the minimal enclosing sphere of the aggregate (i.e. the maximum diameter). Particles are described by elements of a type space $E$

$E=\left\{m_{\mathrm{agg}}, n_{\mathrm{pri}}, m_{\mathrm{ash}}\right\}$,

where $m_{\text {agg }}$ is the total aggregate mass, $n_{\text {pri }}$ is the number of primary particles in the aggregate and $m_{\text {ash }}$ is the mass of ash inside the aggregate. The aggregate mass other than ash is assumed to be carbonaceous material. Carbonaceous material in all particles is assumed to have identical composition and hence exhibits the same behaviour.

The size distribution of the particles is described by the particle number density $N$. The population balance model is solved using a sectional method [43]. The sectional method has been successfully applied in modelling the evolution of soot particle in flames [44, 45] and engines [22, 46]. The particle population is divided into sections (i.e. size classes) according to the value of $m_{\text {agg }}$ for each particle. All primary particles belonging to aggregates within a given size class are assumed to have the same size [22, 45]. In this work, 
population balance equations of the form

$\frac{\mathrm{d} N_{z, j}}{\mathrm{~d} t}=Q_{z, j} \dot{N}_{z, j-1}, \quad j \in S_{\mathrm{ci}} \cup S_{\mathrm{pm}} \cup S_{\mathrm{co}}$

are solved for $N_{\mathrm{agg}}, N_{\text {pri }}$ and $N_{\mathrm{ash}}$, corresponding to each element of the type space defined in Eq. (3) and representing the total number density of aggregates, primary particles and equivalent ash mass in a size class. $Q_{z, j}$ is the filtration efficiency of particles of size $z$ calculated from the filtration model (see Section 2.2). $\dot{N}_{z, j-1}$ is the rate of change of the number density of particles flowing from volume element $j-1$ to volume element $j$

$\dot{N}_{z, j}=\left(1-Q_{z, j}\right) \dot{N}_{z, j-1}, \quad j \in S_{\mathrm{ci}} \cup S_{\mathrm{pm}} \cup S_{\mathrm{co}}$.

The mass of an aggregate $m_{\text {agg }}$ for a given size class is known a priori. The other type space variables are calculated

$$
\begin{aligned}
n_{\mathrm{pri}, z, j} & =\frac{N_{\mathrm{pri}, z, j}}{N_{\mathrm{agg}, z, j}}, \\
m_{\mathrm{ash}, z, j} & =m_{\mathrm{agg}, z, j} \frac{N_{\mathrm{ash}, z, j}}{N_{\mathrm{agg}, z, j}} .
\end{aligned}
$$

The primary particle diameter is calculated

$d_{\mathrm{pri}, z, j}^{3}=\frac{6}{\pi} \frac{m_{\mathrm{agg}, z, j}}{n_{\mathrm{pri}, z, j} \rho_{\mathrm{agg}, z, j}}$,

where $\rho_{\text {agg }}$ is the material density of the aggregate.

\subsection{Filtration Model}

The filtration of the particles is described using the classic unit collector model [47]. The unit collector model is used to calculate the filtration efficiencies and permeabilities that are required in Eqs. (2) and (4). The unit collector model has been widely adopted in particulate filter modelling studies [48]. It considers the filter wall as a bed of spherical unit collectors. The model approximates the gas flow through the porous wall as the gas flow around a spherical unit collector and is able to describe the filtration of particles via diffusion and interception [47, 48], as illustrated in Fig. 4.
The diameter of the collector $d_{\text {collo }}$ representing the clean porous wall is calculated as [49]

$d_{\mathrm{coll0}}=\frac{3}{2} \frac{1-\epsilon_{\mathrm{w} 0}}{\epsilon_{\mathrm{w} 0}} d_{\mathrm{pore} 0}$,

where $\epsilon_{\mathrm{w} 0}$ and $d_{\text {pore } 0}$ are the porosity and pore diameter of the clean porous wall, and are inputs to the model. The filtration efficiencies of the porous wall and the ash layer are calculated using equations of the form

$Q_{z, i}=1-\exp \left[-\frac{3 \eta_{z, i}\left(1-\epsilon_{i}\right) w_{i}}{2 \epsilon d_{\mathrm{coll}, i}}\right]$,

where $\epsilon$ is the porosity of the filter medium, $w$ is the thickness of the filter medium, $d_{\text {coll }}$ is the diameter of the collector and $\eta$ is the efficiency of a single collector. The single collector efficiency $\eta_{z, i}$ and hence the filtration efficiency $Q_{z, i}$ depends on both the size of the particles (indexed by $z$ ) and the state of the filter medium in volume element $i$. The values of $\epsilon, d_{\text {coll }}$ and $w$ depend on the volume element index $i$ which indicates whether the volume element represents the filter wall or the ash layer. In the case of the porous wall, the thickness of the wall is treated as a constant, whereas the porosity and collector diameter are calculated based on the particulate loading within the wall (see Section 2.2.1). In the case of the ash layer, the porosity and collector diameter are inputs to the model and are treated as constants during simulations. The thickness of the ash layer is a function of the mass of ash accumulated on the surface of the filter wall. The contribution of the soot cake layer towards filtration is described in Section 2.2.2.

The single collector efficiency $\eta$ in Eq. (10) combines contributions from diffusion and interception (see Fig. 4). These two mechanisms are assumed to act independently, such that

$\eta_{z, i}=\eta_{\mathrm{D}, z, i}+\eta_{\mathrm{R}, z, i}-\eta_{\mathrm{D}, z, i} \eta_{\mathrm{R}, z, i}$

where subscripts $\mathrm{D}$ and $\mathrm{R}$ refer to diffusion and interception respectively. In general, smaller particles are more likely to be trapped by diffusion since they are more susceptible to
Fig. 4 The unit collector model approximates the flow in the porous wall as gas flow through a bed of equivalent spherical collectors. Particles may be trapped by the collectors via diffusion ("D") and interception ("R")

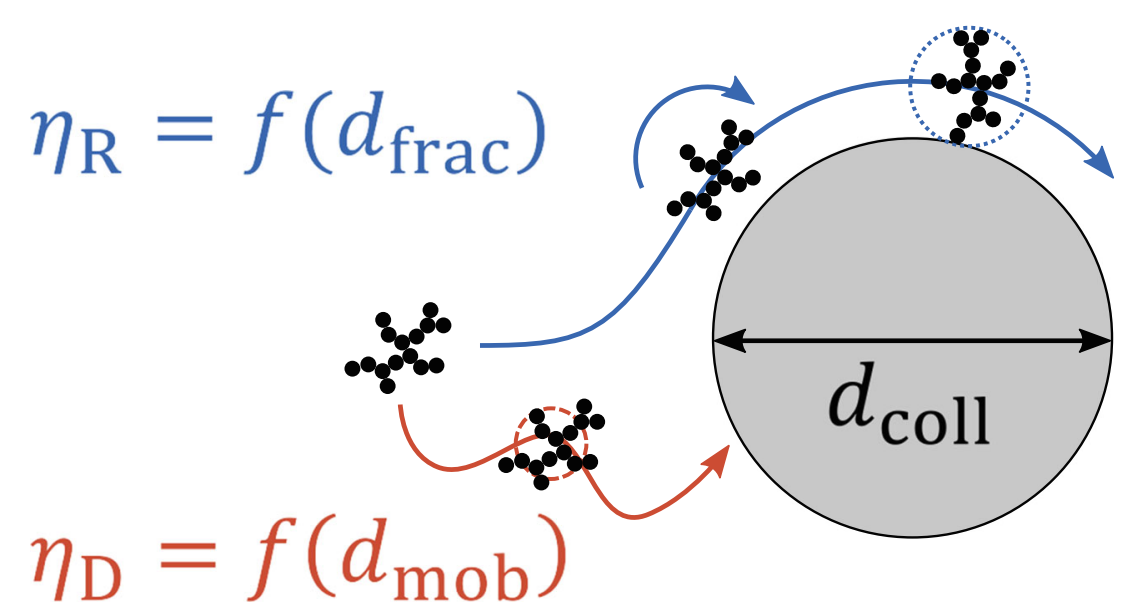


the impact of Brownian motion. In contrast, larger particles are more likely to be trapped by interception.

The diffusional single collector efficiency $\eta_{\mathrm{D}}$ is a function of the filter porosity and the Peclet number of the particle [47, 48]

$\eta_{\mathrm{D}, z, i}=3.5 g\left(\epsilon_{i}\right) \mathrm{Pe}_{z, i}^{-\frac{2}{3}}$,

where $g(\epsilon)$ is a Kuwabara geometric function

$\left[g\left(\epsilon_{i}\right)\right]^{3}=\frac{\epsilon_{i}}{2-\frac{9}{5}\left(1-\epsilon_{i}\right)^{\frac{1}{3}}-\epsilon_{i}-\frac{1}{5}\left(1-\epsilon_{i}\right)^{2}}$,

and $\mathrm{Pe}$ is the Peclet number which is calculated as per Konstandopoulos et al. [48]. The relevant length scale for the Peclet number is the mobility diameter of the particle $d_{\text {mob. This is calculated as per Sorensen [42] }}$

$d_{\mathrm{mob}, z, i}=\left\{\begin{array}{r}d_{\mathrm{pri}, z, i} n_{\mathrm{pri}, z, i}^{0.46} n_{\mathrm{pri}, z, i}<100 \\ 0.65 d_{\mathrm{pri}, z, i} n_{\mathrm{pri}, z, i}^{0.56} n_{\mathrm{pri}, z, i} \geq 100\end{array}\right.$,

where $d_{\text {pri }}$ is the diameter of the primary particles within the aggregate. The values of $d_{\text {pri }}$ and $n_{\text {pri }}$ are calculated as per Eqs. (6) and (8).

The interceptional single collector efficiency $\eta_{\mathrm{R}}$ is calculated by $[47,48]$

$\eta_{\mathrm{R}, z, i}=\frac{3}{2}\left[g\left(\epsilon_{i}\right)\right]^{3} \frac{R_{z, i}^{2}}{\left(1+R_{z, i}\right)^{1-\frac{2}{3 \epsilon_{i}}}}$,

where $R$ is the interception parameter

$R=\frac{d_{\mathrm{frac}, z, i}}{d_{\mathrm{coll}, i}}$,

defined in terms of the collector diameter $d_{\text {coll }}$, see Eq. (10), and the fractal diameter of the aggregate $d_{\text {frac }}$ [45]

$d_{\mathrm{frac}, z, i}=d_{\mathrm{pri}, z, i}\left(V_{f} n_{\mathrm{pri}, z, i}\right)^{\frac{1}{D_{f}}}$,

where the volume filling factor $V_{f}$ and the fractal dimension $D_{f}$ are set to 1.43 and 1.8 respectively [45]. The volume filling factor is a scaling constant that is similar to the fractal prefactor as reported by Sorensen and Roberts [50]. The choice of fractal diameter as the relevant length scale in the ratio defined by Eq. (16) follows from the assumption that a particle will be collected by interception when the streamline carrying the particle passes within one particle radius of the collecting body [51].

\subsubsection{Treatment of Clogged Filter Wall}

As particles accumulate in the porous wall, the pore volume available for gas flow is reduced, and the pressure drop of the filter increases accordingly. This implies a decrease in the permeability of the porous wall $\kappa_{\mathrm{W}}$ which is used in Eq. (2). The unit collector model calculates the permeability of the wall as [48]

$\kappa_{\mathrm{w}, i}=\kappa_{\mathrm{w} 0, i} \frac{d_{\mathrm{coll}, i}^{2}}{d_{\mathrm{coll} 0, i}^{2}} \frac{f\left(\epsilon_{\mathrm{w}, i}\right)}{f\left(\epsilon_{\mathrm{w} 0, i}\right)}$,

where $\epsilon_{\mathrm{w} 0}$ and $\epsilon_{\mathrm{w}}$ are the porosity of the clean wall and the clogged wall. The permeability of the clean wall $\kappa_{\mathrm{w} 0}$ is provided as an input to the model. The porosity of the clogged wall is a function of the collector diameter of the clogged wall $d_{\text {coll }}[48,52]$

$\epsilon_{\mathrm{w}, i}=1-\left(1-\epsilon_{\mathrm{w} 0, i}\right) \frac{d_{\mathrm{coll}, i}^{3}}{d_{\mathrm{coll}, i}^{3}}$,

which increases with the mass of particles accumulated in the wall $[48,52]$

$d_{\mathrm{coll}, i}^{3}=d_{\mathrm{coll}, i}^{3}+\frac{6}{\pi} \frac{m_{\mathrm{p}, \mathrm{w}, i}}{\rho_{\mathrm{w}}}$,

where $m_{\mathrm{p}, \mathrm{w}}$ and $\rho_{\mathrm{w}}$ are the mass and packing density of the particles accumulated in the porous wall. The mass of particles $m_{\mathrm{p}, \mathrm{w}}$ is solved by the model. The packing density $\rho_{\mathrm{w}}$ is a model parameter that is typically calibrated to match experimental observations of the pressure drop across the filter. It should be noted that $\rho_{\mathrm{w}}$ should not be interpreted as the physical bulk density of the ash deposits accumulated in the filter wall, but as the bulk density of particles accumulated in the bed of unit collectors. The accumulation of particles within the pores of the ash layer is neglected in this work. This assumption is based on the experimental observation that no deep-bed filtration occurs when the ash layer is established as shown in Fig. 1.

The function $f(\epsilon)$ appearing in Eq. (18) is the Kuwabara function with the following form [53]

$f\left(\epsilon_{i}\right)=\frac{1}{18} \frac{2-\frac{9}{5}\left(1-\epsilon_{i}\right)^{\frac{1}{3}}-\epsilon_{i}-\frac{1}{5}\left(1-\epsilon_{i}\right)^{2}}{1-\epsilon_{i}}$.

Note that this has a factor of 4 difference from the equation reported by Konstandopoulos et al. [54]. Equation (21) adopts the formulation from Lee et al. [53] which shows better consistency between the experimental pressure drop and primary particle measurements.

\subsubsection{Treatments of Particulate Layers}

As particles accumulate in the porous wall, the filtration mechanism changes and the particles start to form a soot cake at the interface between the wall/ash layer and the inlet channel. The filtration efficiency of the established soot cake layer is assumed to be $100 \%$. The transition from deep-bed filtration to soot cake formation is controlled by the partition coefficient

$\Phi=\frac{d_{\text {coll,interface }}^{2}-d_{\text {collo }}^{2}}{\left(\psi d_{\text {coll,max }}\right)^{2}-d_{\text {collo }}^{2}}$, 
where $d_{\text {coll,interface }}$ is the collector diameter in the volume element of the porous wall at the interface with the inlet channel, $d_{\text {coll,max }}$ is the maximum collector diameter possible, and $\psi$ is the percolation constant. The percolation constant is a model parameter that is typically calibrated to match experimental observations of the change in the rate of increase in the pressure drop across the filter caused by the transition from deep-bed filtration to cake formation (see Fig. 1). The maximum collector diameter $d_{\text {coll,max }}$ is calculated from the porosity of the clean filter wall such that the unit collector has the same capacity for particles as the filter wall [52]

$d_{\text {coll, } \max }^{3}=\frac{d_{\text {collo }}^{3}}{1-\epsilon_{0}}$.

The permeabilities of the soot cake and ash layer required by Eq. (2) are calculated based on their microstructures [54]

$\kappa=f(\epsilon) d^{2} C$,

where $\epsilon$ is the porosity of the particulate layer, $d$ is the diameter of the particles in the layer, $C$ is the StokeCunningham factor accounting for the slip-flow effect

$C=1+\mathrm{Kn}\left(1.257+0.4 \exp \left[-\frac{1.1}{\mathrm{Kn}}\right]\right)$,

and $\mathrm{Kn}$ is the Knudsen number calculated based on the particle diameter $d$. It should be noted that Eq. (24) requires a single value of $d$, even though the particles may be subject to a polydisperse size distribution. In this work, the values of the particle diameter $d$ for the soot cake and ash layer are supplied as single-valued inputs to the model. The value for soot is referenced from the experimental results of Sappok et al. [55] and that for ash is calibrated based on experimental pressure drop measurements of ash-loaded filters.

\subsection{Regeneration Model}

The ash layer is formed on the surface of the inlet channels in the filter from incombustible residues (i.e. ash particles) in the soot cake that are left behind when the soot is burned off during regeneration. The ash layers in the particulate filters studied in this work were deposited over many loading-regeneration cycles [34]. The regeneration events are captured by post-processing simulations of the loading part of each cycle to provide initial conditions for the simulation of the next loading cycle. It is assumed that all the soot is burned off during each regeneration event, that all the ash particles trapped in the soot cake now form part of the ash layer (see Fig. 2), that the properties of the ash (in the ash layer and in the ash deposits in the porous walls of the filter) are unaltered by regeneration and that no axial transport of ash occurs. The consequence of neglecting axial transport of the ash is discussed in detail in Section 3.

\subsection{Thermal Treatment Model}

Two phenomena are expected to occur to ash deposits during the thermal treatment of particulate filters: sintering and crack formation. Both have been observed experimentally [36]. They can also occur during uncontrolled active regeneration events in real operation which may create high interior filter temperature [56], or even normal GPF operation since gasoline exhaust is hotter in general [57]. Sintering can affect the ash-induced pressure drop in two ways. First, it can reduce the bulk volume of ash deposits, which leads to decreased resistance to gas flow since the porous wall will be unblocked and the ash layer will become thinner. Second, sintering can alter the microstructure of the ash layer and therefore its permeability. The permeability of the ash layer can also be affected by crack formation, which allows more gas to flow through and hence results in an increase in the permeability.

The overall permeability of the ash layer $\kappa_{\text {ash }}$ considering the impact of both sintering and cracking is

$\kappa_{\mathrm{ash}}=\kappa_{\mathrm{s}}+\kappa_{\mathrm{c}}$

where $\kappa_{\mathrm{S}}$ and $\kappa_{\mathrm{c}}$ are the contributions to the permeability of the ash layer arising from sintering and cracking respectively. In this work, the impact of the sintering and cracking of the ash deposits is incorporated in the model by post-processing the results of loading-regeneration simulations to modify the properties of the ash deposits to provide initial conditions for subsequent post-thermaltreatment simulations. Model equations for both phenomena are described below.

\subsubsection{Sintering Model}

Sintering between ash particles occurs when the ash is exposed to high temperatures. The sintering leads to a reduction in the bulk volume of the ash deposits. A sintering progress variable $X$ is defined in terms of the relative reduction in bulk volume of ash deposits $V_{\text {ash,bulk }}$

$X=1-\frac{V_{\text {ash,bulk }}}{V_{\text {ash,bulk0 }}}$

where the subscript 0 refers to the volume of the ash deposit prior to thermal treatment. The value of the sintering progress variable is used to update the model input parameters to account for the effect of sintering. It is inferred from experimental measurements as a function of the furnace temperature used in the thermal treatment (see Section 3.3). 
Fig. 5 The combination of the observed range of ash layer porosities and the correlation proposed by Lagemaat et al. [58] suggests that a typical ash layer would have a coordination number in the range $2.1-2.5$, corresponding to a finger-like microstructure. The ash layer structure is approximated as particle columns for the purpose of developing a relationship between the particle size and porosity in the sintering model

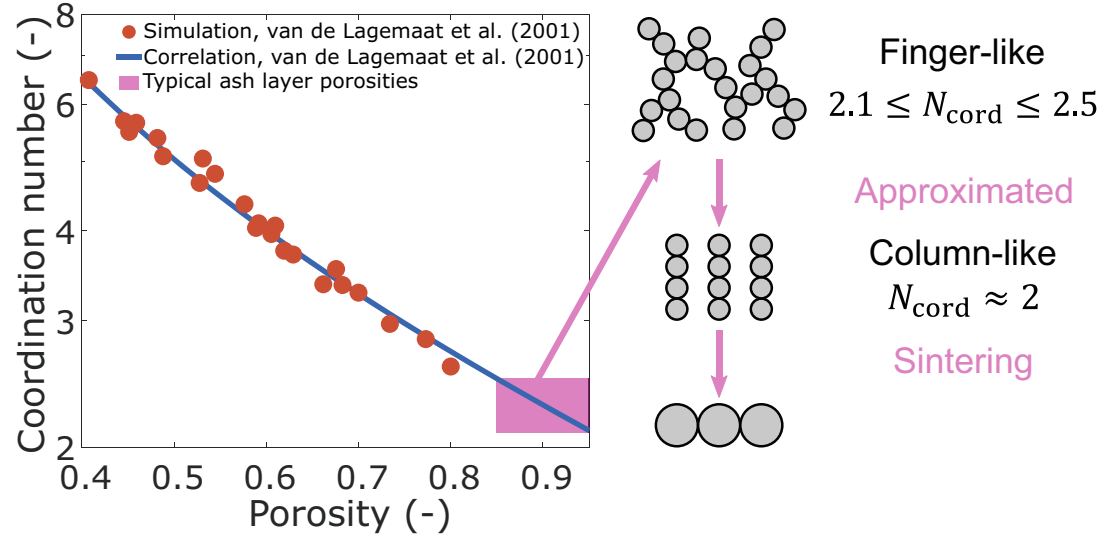

Sintering of Ash in the Filter Walls The effect of sintering of ash in the walls of the filter is modelled by adjusting the packing density $\rho_{\mathrm{W}}$ that appears in Eq. (20)

$\frac{1}{\rho_{\mathrm{w}}}=\frac{1}{\rho_{\mathrm{w} 0}}-X\left(\frac{1}{\rho_{\mathrm{w} 0}}-\frac{1}{\rho_{\mathrm{ash}}}\right)$,

where $\rho_{\mathrm{w} 0}$ is the packing density of unsintered ash deposits and $\rho_{\text {ash }}$ is the material density of the ash $\left(\rho_{\text {ash }}=3400\right.$ $\mathrm{kg} / \mathrm{m}^{3}$ in this work [34]).

Sintering of the Ash Layer The effect of sintering in the ash layer is modelled by adjusting the porosity $\epsilon$ of the ash layer

$\frac{1}{1-\epsilon}=\frac{1}{1-\epsilon_{0}}-X\left(\frac{1}{1-\epsilon_{0}}-1\right)$.

A fully sintered ash layer is expected to have $\epsilon=0$. It is assumed that the porosity is the same everywhere within the ash layer. As a result, the ash layer shrinks uniformly during sintering. In addition to the effect on bulk volume and porosity, sintering effects the permeability of the ash layer. The permeability of the sintered ash layer $\kappa_{\mathrm{S}}$ is evaluated using Eq. (24), which requires the diameter of the particles and the porosity of the ash layer as inputs. Therefore it is necessary to model how sintering affects these two parameters.

The morphology of the ash layer may be deduced from the particle coordination number $N_{\text {cord }}$, which describes the (average) number of neighbouring particles for each particle in a bed of particles. A correlation between $N_{\text {cord }}$ and the porosity of a particle layer $\epsilon$ is reported by Lagemaat et al. [58]

$N_{\text {cord }}=\frac{3.08}{\epsilon}-1.13$.

The correlation is shown in Fig. 5. Typical ash deposits have a porosity in the range 0.85-0.95 [15], implying a coordination number $N_{\text {cord }}$ in the range 2.1-2.5. This is consistent with the finger-like structures predicted by particle deposition simulation studies [59].
In order to derive a relationship between the porosity and the diameter of the particles in the ash layer during sintering, the microstructure of the ash is approximated as having column-like structures, corresponding to $N_{\text {cord }} \approx 2$. The following relationship between the porosity $\epsilon_{\text {ash }}$ and the diameter $d_{\text {ash }}$ of the particles in the ash layer can be derived

$\epsilon_{\mathrm{ash}}=1-\frac{1-\epsilon_{\mathrm{ash} 0}}{d_{\mathrm{ash} 0}^{2}} d_{\mathrm{ash}}^{2}$,

subject to the assumption that all primary particles in the ash layer have the same size and that sintering causes the particles in the columns to merge and grow until they form a mono-layer of particles in point contact. These assumptions are illustrated in Fig. 5. In other words, the necking phenomenon between neighbouring particles during sintering is neglected. This can lead to a maximum of $33 \%$ underestimation of the permeability [60]. It is shown later in Section 3.3 that this does not incur significant error. The symbols $\epsilon_{\mathrm{ash} 0}$ and $d_{\mathrm{ash} 0}$ denote the porosity and particle diameter of the ash layer prior to thermal treatment. The detailed derivation of the relationship in Eq. (31) is given in Appendix A. Note that the relationship breaks down once the particles sinter beyond the mono-layer. The porosity of a mono-layer is $1-\frac{\pi}{6} \approx 0.417$. If the porosity of the ash layer prior to thermal treatment $\epsilon_{0} \geq 85 \%$, then Eq. (31) is subject to the limit $X \leq 0.713$. These limits are never exceeded in this work.

Sintering of the Ash Plug In the case of an ash plug, the effect of sintering is modelled by adjusting the length of the ash plug

$L_{\text {plug }}=L_{\text {plug0 }}-X\left(L_{\text {plug0 }}-\min \left[L_{\text {plug }}\right]\right)$,

where $\min \left[L_{\text {plug }}\right]$ is calculated under the assumption that a fully sintered ash plug would have the material density of the ash. As the modelled ash plug shrinks, a new portion of the filter wall and ash layer are exposed to the gas flow in the inlet channel. The state of this portion of the wall and ash layer are not tracked by the model (see Fig. 2(b)). 
In this work, it is assumed that they have the same state as the upstream neighbouring volume elements in the inlet channel. This approach is supported by the observation that the axial variation of ash deposits in the porous wall predicted by the model is negligible $(\leq 1 \%)$. This is substantiated in Fig. 17 in the Appendix.

\subsubsection{Cracking Model}

Crack formation in ash layers has been observed after thermal treatment [36]. The cracks significantly increase the permeability of the damaged ash layer. Mahadevan et al. [61] adapted a damage permeability function from a study of concrete [62] to model the damage to a soot cake during regeneration

$\kappa_{\mathrm{d}}=\kappa_{0} \exp \left[(A D)^{B}\right]$,

where $\kappa_{\mathrm{d}}$ is the permeability of the damaged media, $\kappa_{0}$ is the permeability of the intact media, $A$ and $B$ are model parameters and $D$ is a damage variable. The actual form of $D$ depends on context: it was chosen to be the dimensionless soot cake mass by Mahadevan et al. [61] and the relative change in elastic modulus by Picandet et al. [62].

Whilst Eq. (33) has been shown to be consistent with experimental observations, two problems need to be solved before it can be applied to the thermal treatment of ash. Firstly, Eq. (33) needs to be modified in order to consider the impact of sintering. If sintering occurs, $\kappa_{0}$ would not be constant. The change in permeability due to the cracks alone $\kappa_{\mathrm{c}}$ is [61]

$\kappa_{\mathrm{c}}=\kappa_{\mathrm{d}}-\kappa_{0}=\kappa_{0}\left(\exp \left[(A D)^{B}\right]-1\right)$.

Secondly, Eq. (33) can predict extremely high permeabilities for severely damaged media, which leads to numerical difficulties in the solution procedure. This was addressed by Pijaudier-Cabot et al. [63] who opted to use a Taylor expansion of Eq. (33) to avoid the rapid increase in permeability for severely damaged media. In this work an alternative formulation of the cracking model in Eq. (34) is proposed

$$
\frac{\kappa_{\mathrm{c}}}{\kappa_{0}}=\theta+\gamma\left(X-\frac{1}{\alpha} \exp [\alpha(X-\beta)]\right),
$$

where $\alpha, \beta, \gamma$ and $\theta$ are model parameters. The damage variable is chosen to be the sintering progress variable $X$, see Eq. (27). The apparent increase in number of parameters is negated by imposing two additional boundary conditions. First, the minimum value of the crack permeability $\kappa_{\mathrm{c}}$ is set to be $10^{-19} \mathrm{~m}^{2}$. This value corresponds to granite which is practically impervious to gas flow [64]. Second, the maximum value of $\kappa_{\mathrm{c}}$ is chosen to be 3 orders of magnitude higher than the permeability undamaged media $\kappa_{0}$. If the pressure drop due to the undamaged media is $O\left(10^{3}\right) \mathrm{Pa}$, then the pressure drop of the damaged media is capped at $O(1) \mathrm{Pa}$, sufficiently smaller than the expected experimental error.

The crack model proposed in this work in Eq. (35) therefore has two degrees of freedom, the same as the cracking model in Eq. (33). Figure 6 compares the two models. The ratio between the permeability of the damaged media and that of the intact media, $\kappa_{\mathrm{d}} / \kappa_{0}$ is presented. Excellent agreement between the models can be observed for $1 \leq \kappa_{\mathrm{d}} / \kappa_{0} \leq 10$, the range of practical interest. At large values of the damage variable, the model used in this work predicts a finite maximum permeability. This provides better numerical behaviour.

\section{Numerical Study and Discussions}

The model was applied to investigate the effect of ash loading and the subsequent thermal treatment of the ash on the pressure drop through a particulate filter by simulating a series of experiments by Sappok et al. [34-37]. All simulations in this work were performed using the same
Fig. 6 The cracking model parameterises the permeability of the ash layer as a function of the damage variable. The model used in this work ensures that the value of the permeability remains finite at large values of the damage variable, whilst retaining good agreement with the original model proposed by Picandet et al. [62] in the region of interest

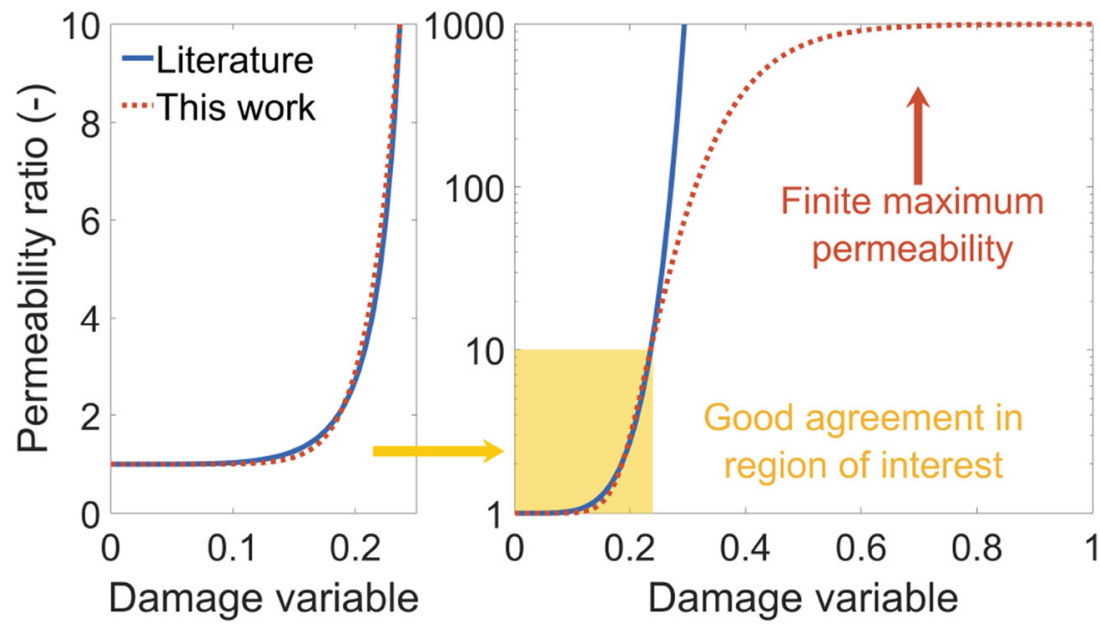


Fig. 7 Schematic of the experimental setup used by Sappok et al. [34-37]. The filter can be subject to in-flow from the engine, the burner or ambient air. The reported pressure drop was always measured with ambient air

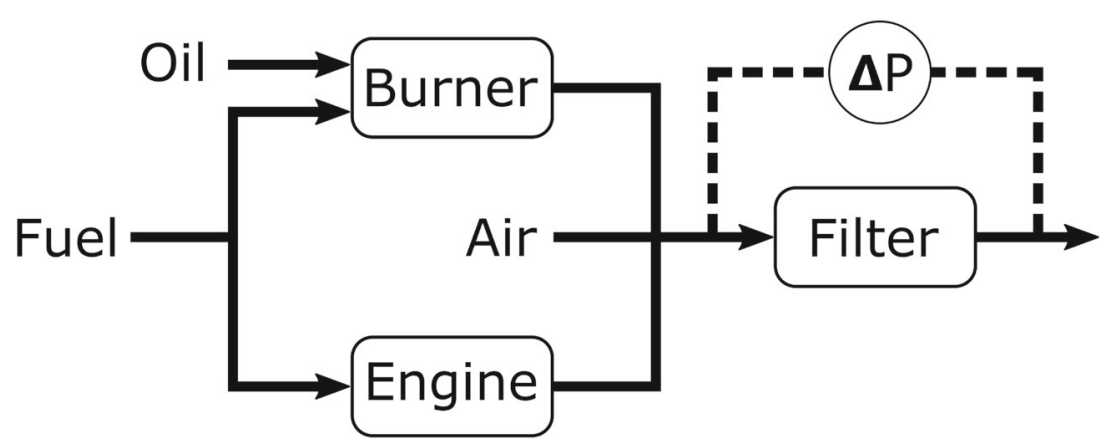

spatial discretisation, where the numbers of control volumes in the axial and the through-wall directions are $n_{\mathrm{ax}}=$ 10 and $n_{\mathrm{w}}=8$ respectively. When the ash plug is present, the portion of the inlet channel available to gas flow is uniformly discretised into 10 control volumes. An additional control volume is added in the outlet channel to represent part of the outlet channel which has no throughwall gas flow due to the presence of the ash plug, as shown in Fig. 2(b). This choice of discretisation is consistent with that in other studies [38, 61].

Key details of the experiments are summarised in Section 3.1. The initial calibration of the model and simulation of the pressure drop whilst loading the filter is reported in Section 3.2. The impact of high temperature exposure on the ash-related pressure drop is investigated in Section 3.3. The implication of the results and suggestions for future studies are discussed in Section 3.4.

\subsection{Experimental Setup}

The experiments modelled in this work were performed using an accelerated ash loading system [34-37]. The experimental setup is shown in Fig. 7. Two particle sources were included in the accelerated loading system. A Cummins ISB 300 diesel engine that emitted soot aggregates with negligible ash content, and a custom-made burner equipped with an oil injector. The burner was used to emit soot aggregates with various levels and compositions of ash content depending on the type and rate of injection of lubricant oil into the burner. A downstream filter was loaded with particles from either the engine or the burner. This work focuses on experiments with platinum-coated DPFs [36].

The experiments were performed to measure the pressure drop across the filter in four steps. First, the pressure drop was measured at different space velocities when the filter was clean (i.e. without any particle loading). Second, the filter was loaded with particles from the engine and the pressure drop measured as a function of soot loading. Third, the filter was loaded with particles from the burner, using CJ-4 engine oil to provide a source of ash. The ash was allowed to accumulate in the filter over multiple loadingregeneration cycles, and the pressure drop measured as a function of ash loading after each regeneration event. Two sets of measurements were performed. One that stopped when the filter reached a nominal ash loading of $12.5 \mathrm{~g} / \mathrm{L}$, the other when the filter reached $42 \mathrm{~g} / \mathrm{L}$. Fourth, once each filter reached its target loading, a cylindrical core sample was removed from the filter and subsequently heated at $650^{\circ} \mathrm{C}$ for an hour to ensure that no soot remained within the sample. The samples were then heated in a furnace at a specified temperature for 30 minutes before measuring the pressure drop across each filter sample. This was repeated for furnace temperatures increasing from 650 to $1100^{\circ} \mathrm{C}$. Finally, note that the reported pressure drops were all measured using ambient air.

\subsection{Model Calibration}

In order to study the impact of thermal treatment on the pressure drop of ash-contaminated filters, the spatial distribution of ash within the porous wall, along the inlet channel surface and within the ash plug must be known. Likewise, the porosity and the size of the particles in the ash layer must be known in order to evaluate the permeability using Eq. (24). Whilst the porosity and thickness profile of the ash in selected filter channels are reported [65], the spatial distribution of the ash in the filter wall and the size of the particles in the ash layer are unknown.

The unknown model parameters (including the size of the particles in the ash layer) are estimated by progressively calibrating the model against experimental data, initially for the pressure drop across a clean filter, then for the pressure drop across a soot-loaded filter and eventually for the pressure drop across an ash-loaded filter. Once this is complete, the spatial distribution of the ash in the filter wall can be obtained as an output from the calibrated model.

The rest of the section is organised as follows. First, the contribution of the clean filter towards overall pressure drop is investigated in Section 3.2.1. Second, the unit collector model is calibrated using data from soot filtration experiments in Section 3.2.2. Finally, ash accumulation 
Fig. 8 Pressure drop across a clean filter. The model shows good agreement with the experimental data reported by Sappok et al. [34]

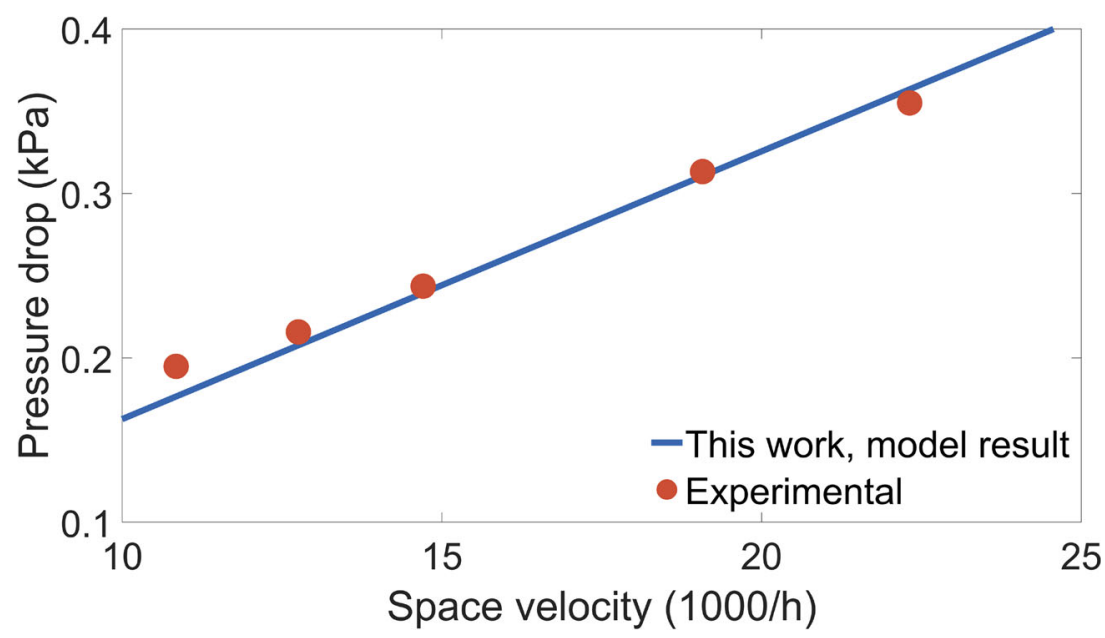

experiments are simulated in Section 3.2.3, where the model is used to estimate the particle diameter and spatial distribution of the ash deposits.

\subsubsection{Pressure Drop Across a Clean Filter}

The pressure drop across the clean filter arises due to frictional losses in the flow along the channels and through the porous wall. These losses are included in the model via Eqs. (1) and (2). Losses due to contraction and expansion are neglected since they are only significant at high flow rates [66]. Since the frictional loss along the channels is determined by the geometry of the filter, only the permeability of the clean filter wall $\kappa_{\mathrm{w} 0}$ needs to be calibrated. The calibration is executed as per Tronconi et al. [67].

A comparison of the pressure drop predicted by the model versus experimental data [34] for a clean filter is shown in Fig. 8. Good agreement is observed. The pressure drop increases with the space velocity. The experimental pressure drop has a linear relationship with the space velocity, indicating that the inertial pressure drop across the filter is negligible. The value of $\kappa_{\mathrm{w} 0}$ after calibration was $1.3 \times 10^{-13} \mathrm{~m}^{2}$. This value was held constant for all subsequent simulations in this work.

\subsubsection{Pressure Drop During Soot Filtration Loading}

The unit collector model was calibrated in order to simulate how the filtration 1efficiencies and permeabilities in Eqs. (2) and (4) change during soot (and ash) loading.

The porosity $\epsilon_{\mathrm{w} 0}$ and the pore diameter $d_{\mathrm{pore} 0}$ of the clean filter wall are required as model inputs. No filtration efficiency measurements were reported for the filters considered in this study, so the values of these parameters could not be estimated as per Lao et al. [38]. Rather, the Rumpf-Gupte correlation [68]

$\kappa_{\mathrm{w} 0}=\frac{1}{5.6} \epsilon_{\mathrm{w} 0}^{5.5} d_{\mathrm{pore} 0}^{2}$,

was used to estimate $\epsilon_{\mathrm{w} 0}$ and $d_{\text {pore } 0}$ from the calibrated value of $\kappa_{\mathrm{w} 0}$. It was assumed that $d_{\text {pore } 0}$ has a value of $10 \mu \mathrm{m}$ in this work. This is on the lower end of the typical range of pore diameters $(10-30 \mu \mathrm{m}$ [65]), but is consistent with the fact that the filters considered in this study are coated with a platinum-based catalyst, and are therefore expected to have smaller pore diameters than uncoated filters. The corresponding value of $\epsilon_{\mathrm{w} 0}$ was $41 \%$, which is considered to be reasonable for a coated filter. In practice these two parameters could also be measured experimentally (e.g. using X-ray tomography [69]). The remaining unit collector parameters were calibrated as per Kladopoulou et al. [52] and Zhang et al. [70]

- Particle packing density in porous wall $\rho_{\mathrm{w}}=8.0 \mathrm{~kg} / \mathrm{m}^{3}$.

- $\quad$ Soot cake porosity $\epsilon_{\text {cake }}=0.958$.

- Percolation constant $\psi=0.96$.

The particle packing density is within the range of values reported in the literature $(6.24-14.1)$ [48, 71]. The soot cake porosity is within the range of $0.93-0.97$ suggested by Liu et al. [72]. The percolation constant is the similar to that reported by Gong et al. [73] (0.95).

Figure 9 shows the pressure drop predicted by the calibrated model during soot loading. Good agreement is observed with the experimental data reported by Sappok et al. [34]. The following assumptions were made in the simulations.

- The in-situ density of soot particles was $1800 \mathrm{~kg} / \mathrm{m}^{3}$ [74].

- The space velocity of the soot filtration experiment was $200001 / \mathrm{h}$, which is the same as the space velocity used for pressure drop measurement (see Section 3.1). 
Fig. 9 Pressure drop versus soot load. The calibrated model shows good agreement with the experimental data reported by Sappok et al. [34]. The change in gradient at $0.5 \mathrm{~g} / \mathrm{L}$ is due to the transition between deep-bed filtration and soot cake formation as illustrated in Fig. 1

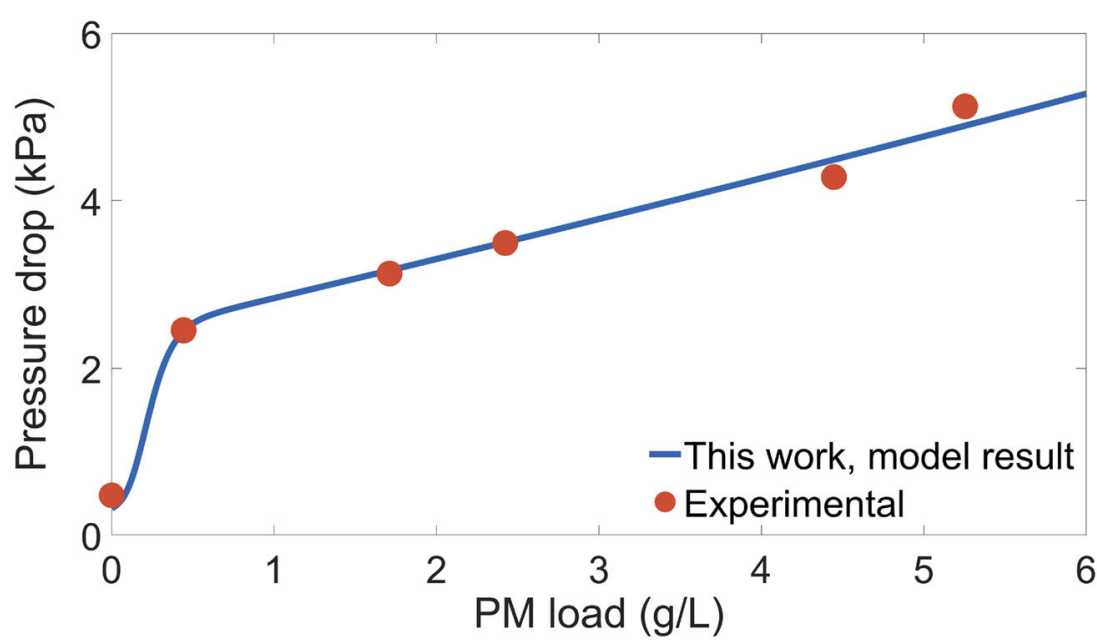

- The morphology of the inlet soot particles was assumed to be the same as those produced by ISB 300 engine at $25 \%$ load [55]. The number of primary particles per aggregate was estimated using Eq. (17). The values of the volume filling factor and the fractal dimension are set according to Eaves et al. [45] and the result shown in Fig. 9 is not sensitive to these parameters.

- The soot filtration experiment operated at $300{ }^{\circ} \mathrm{C}$ [55].

- No passive regeneration occurred at this condition.

\subsubsection{Pressure Drop due to Ash}

The model was applied to simulate the ash loading of the filter. The experimental investigation of the system used an accelerated loading system that consisted of multiple loading-regeneration cycles in which the filter was loaded with burner-generated particles at $250^{\circ} \mathrm{C}$ for $60 \mathrm{~min}$, and then regenerated at $620^{\circ} \mathrm{C}$ for $15 \mathrm{~min}$ every cycle [35]. Data from two experiments were reported. One that loaded a filter up to a nominal ash load of $12.5 \mathrm{~g} / \mathrm{L}$, the other that loaded a filter up to a nominal ash load of $42 \mathrm{~g} / \mathrm{L}$. Timeresolved simulations were performed for the loading part of each experiment. The simulations were stopped after each loading cycle, the results post-processed to account for regeneration, and then restarted to simulate the next loading cycle as described in Section 2.3.

Figure 10 shows the pressure drop at the end of each loading-regeneration cycle versus the ash load accumulated in the filter. The model (black line) uses a calibrated value of $220 \mathrm{~nm}$ for the size of the particles in the ash layer. This value affects both the filtration efficiency and permeability of the ash layer (see Section 2.2). The filtration efficiency of the ash layer controls the proportion of ash deposited in the wall, and hence the point at which the transition from deepbed to cake filtration is observed. The permeability controls the subsequent rate of increase in the pressure drop as the ash layer grows during cake formation.
The calibrated model shows good agreement with the experimental data up to $40 \mathrm{~g} / \mathrm{L}$ ash load. At ash loads above this, the model overestimates the pressure drop. The discrepancy is possibly related to the choice to neglect the axial transport of ash in the model. One consequence of this is that the model cannot describe the formation of an ash plug, and instead predicts an ash layer that is almost uniform in thickness. The predicted ash layer profiles are shown in Fig. 11. Without considering axial transport of ash, the predicted ash layer profiles are determined by the throughwall velocity profiles during the ash accumulation. This is reasonable at low ash loads, but disagrees with experimental observations at high ash loads, which show that the ash plug can occupy 32-48\% of the inlet channel [65].

Sappok [65] measured the ash layer profile in three inlet channels of the filters used in each experiment shown in Fig. 10. In order to investigate the impact of the ash layer, additional simulations were performed in which the experimental ash layer profiles were imposed on the model. The imposed profiles are shown in Fig. 11 and were taken as the average of the profiles measured in each filter. In addition, the ash load in each simulation was imposed based on the ash load implied by the volume of the imposed profile, corresponding to $21.1 \mathrm{~g} / \mathrm{L}$ and $38.0 \mathrm{~g} / \mathrm{L}$, as opposed to the nominal ash loads of $12.5 \mathrm{~g} / \mathrm{L}$ and $42 \mathrm{~g} / \mathrm{L}$ respectively. It is hypothesised that the difference between the ash loads implied by the imposed profiles and the nominal ash loads arises due to variations between the channels in each filter. As a consequence of this, the pressure drops calculated by the simulations with the imposed ash layer profiles are discussed in the context of the pressure drop across the simulated channel-pairs, as opposed to the pressure drop across the entire filter.

The hollow circles on Fig. 10 show the channel-pair pressure drops calculated after imposing the experimental ash layer profiles on the model. The predicted pressure drop for the lightly ash-loaded (nominal $12.5 \mathrm{~g} / \mathrm{L}$ ) filter 
Fig. 10 Pressure drop after regeneration versus the ash load accumulated in the filter. The soot load for all pressure drop data shown in the figure is $0 \mathrm{~g} / \mathrm{L}$. The pressure drop of the ash-loaded filters predicted by the model is compared against experimental measurements reported by Sappok et al. [34]. The model describes lightly loaded filters adequately, but the pressure drop is overestimated at high ash loading if ash migration along the channel is neglected

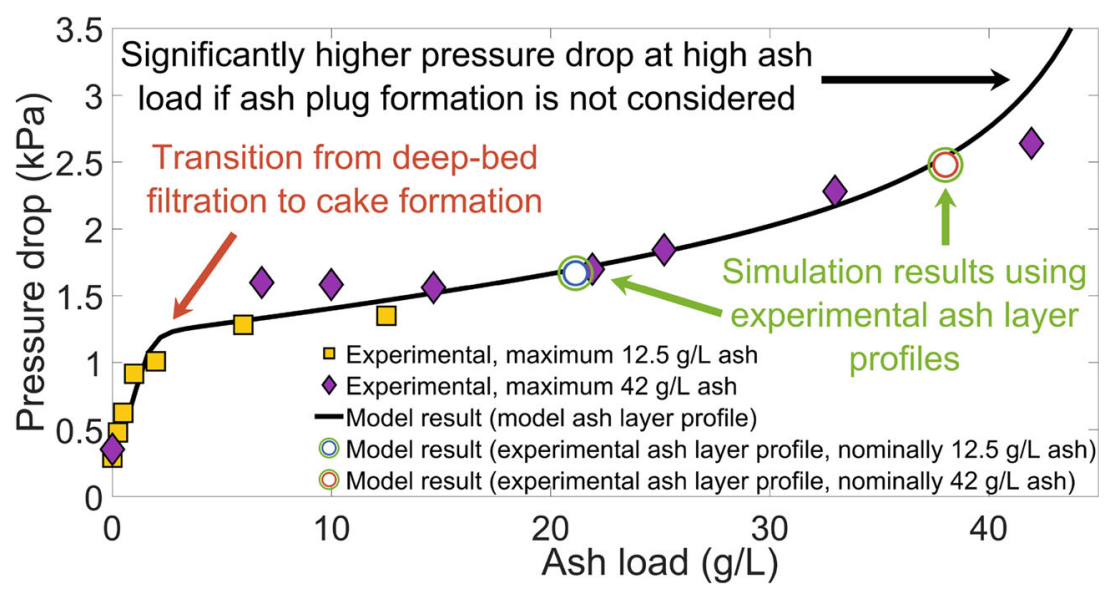

is almost unchanged. This suggests that the pressure drop is insensitive to the shape of the ash layer profile at this ash load. On the other hand, the imposed ash layer profile had a significant effect on the simulation of the heavily ash-loaded (nominal $42 \mathrm{~g} / \mathrm{L}$ ) filter, resulting in a pressure drop of approximately $3.5 \mathrm{kPa}$ (not shown). This suggests that the model underestimated the permeability of the ash layer of the heavily ash-loaded (nominal $42 \mathrm{~g} / \mathrm{L}$ ) filter using experimentally measured ash layer porosity $(0.911)$ and calibrated ash particle diameter $(220 \mathrm{~nm})$.

In order to investigate the impact of thermal treatment on the pressure drop (in the next section), the simulation of the heavily ash-loaded (nominal $42 \mathrm{~g} / \mathrm{L}$ ) filter shown on Fig. 10 was re-calibrated to use a value of $350 \mathrm{~nm}$ for the size of the particles in the ash layer. It is noted that Sappok [65] found that the ash layer in the heavily loaded filter had a lower porosity (0.911) than that in the lightly loaded filter (0.946), which may be indicative of an increase in particle size due to sintering or particle growth due to addition of ash precursor during the repeated regeneration events. By assumption, sintering during regeneration is excluded from the model, and the impact of its omission remains an open question. Finally, it should be emphasised that all other simulation results shown in Fig. 10 were generated using the original value of $220 \mathrm{~nm}$ for the size of the particles in the ash layer.

Figure 12 shows the amount of ash accumulated in the filter wall and in the ash layer at the end of each loadingregeneration cycle. The data correspond to the model result (black line) shown in Fig. 10 and apply to both the $12.5 \mathrm{~g} / \mathrm{L}$ and $42 \mathrm{~g} / \mathrm{L}$ filters. The ash load in the filter wall reaches a maximum value of $0.12 \mathrm{~g} / \mathrm{L}$ after four cycles. No further particle deposition within the filter wall occurs after this point, indicating that the filtration efficiency of the ash layer is now $100 \%$. The total ash load in the filter at this point is estimated to be $2.2 \mathrm{~g} / \mathrm{L}$. Given that the filter wall is saturated at low ash loads, the ash plug (if it is present) would have negligible impact on the ash deposition in the wall.

\subsection{Impact of Thermal Treatment}

Sappok et al. [36] observed that the pressure drop across the ash-loaded filters decreased after the filters were heated in a furnace, with higher furnace temperatures resulting in larger
Fig. 11 Ash layer profiles from experimental measurements and simulation results
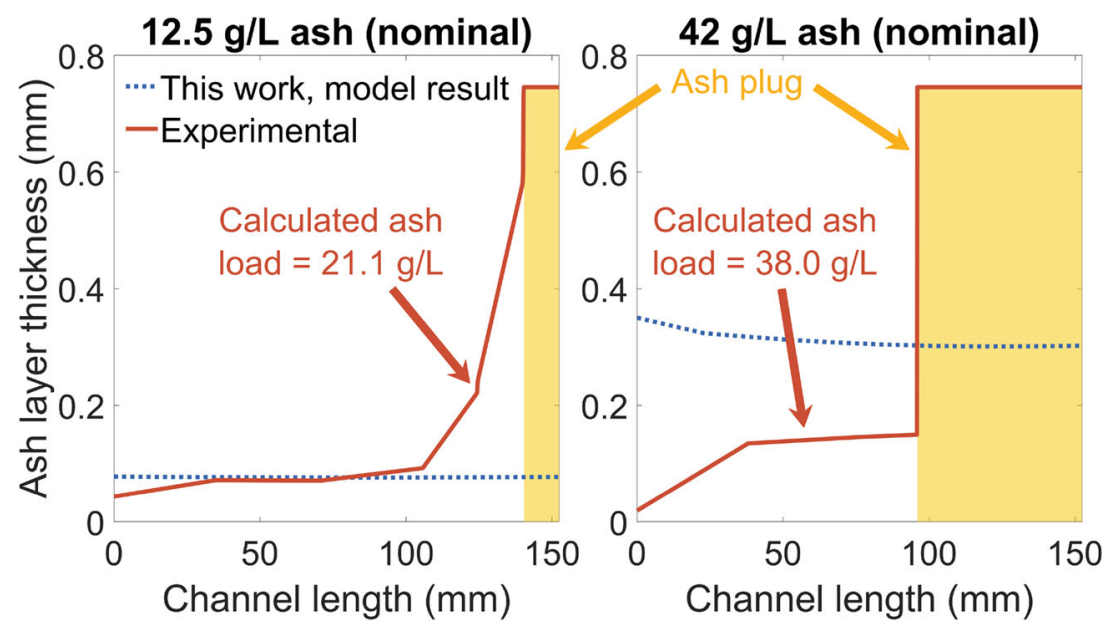
Fig. 12 Ash load in the filter wall and in the ash layer at the end of each

loading-regeneration cycle. The ash load in the filter wall reaches a maximum value of $0.12 \mathrm{~g} / \mathrm{L}$ after four cycles. The total ash load at this point is $2.2 \mathrm{~g} / \mathrm{L}$

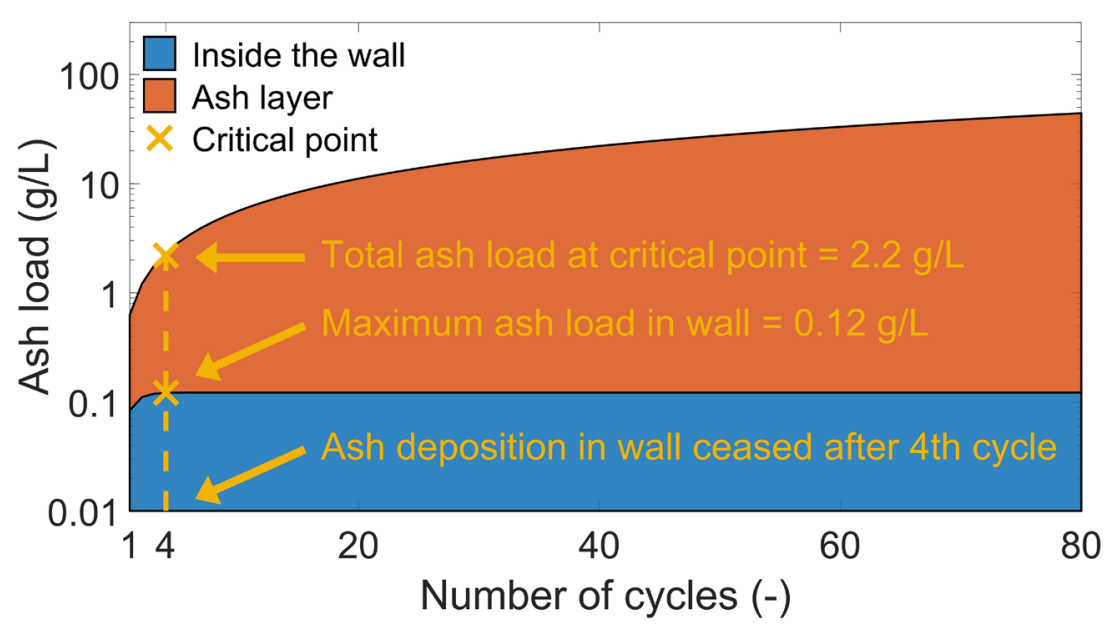

decreases in the pressure drop. The model developed in this work was applied to investigate the mechanisms responsible for this decrease in the pressure drop. On the other hand, experimental results showed that high gas flow condition had negligible impact on the ash-loaded filter samples [36]. As a result, this work does not consider any flow-induced rearrangement of ash deposits.

Figure 13 shows the experimental measurements of the pressure drop across the thermally treated filters versus the furnace temperature [36]. In addition, the figure shows the pressure drop over individual channel-pairs from each filter. The points at $650^{\circ} \mathrm{C}$ were simulated using the imposed experimental ash layer profiles (these data are also shown in Fig. 10). The points at $700-900^{\circ} \mathrm{C}$ were estimated based on the corresponding experimental measurements across the entire filter and the simulation results at $650^{\circ} \mathrm{C}$. It should be noted that the pressure drop over the channelpair in the lightly loaded (nominal $12.5 \mathrm{~g} / \mathrm{L}$ ) filter is larger than the pressure drop measured across the entire filter. This is consistent with the difference between the ash load implied by the imposed ash layer profile $(21.1 \mathrm{~g} / \mathrm{L})$ versus the nominal ash load $(12.5 \mathrm{~g} / \mathrm{L})$, as discussed in Section 3.2.3. The discrepancy is less severe for the heavily loaded (nominal $42 \mathrm{~g} / \mathrm{L}$ ) filter.

Both filters show similar pressure drops for furnace temperatures of $900^{\circ} \mathrm{C}$ and above. This suggests that the ash loading in the wall (which is the same for both filters, see Fig. 12) dominates the pressure drop and that the ash layer and the ash plug (which are different between the two filters) has negligible impact at these conditions. One consequence of this is that the channel-pairs also show the same pressure drop as the filters under these conditions.

The thermal treatment model (see Section 2.4) uses the change in the bulk volume of the ash to define the sintering process variable $X$ which governs the shrinkage of ash deposits within the wall, ash layers and ash plugs. In this work, the relationship between the bulk volume of the ash and the furnace temperature is known experimentally from dilatometer testing of ash samples removed from the filters [36]. Measurements were performed using ash from
Fig. 13 Pressure drop of thermally treated particulate filters versus furnace temperature. The soot load for all pressure drop data shown in the figure is $0 \mathrm{~g} / \mathrm{L}$. Solid circles: Experimental data [36]. Hollow circles: Estimates of the pressure drop across individual channel-pairs. The points at $650^{\circ} \mathrm{C}$ were simulated using the imposed experimental ash layer profiles (these data were also shown in Fig. 10). The points at 700-900 ${ }^{\circ} \mathrm{C}$ were estimated based on the corresponding experimental measurements across the entire filter and the simulation results at $650^{\circ} \mathrm{C}$

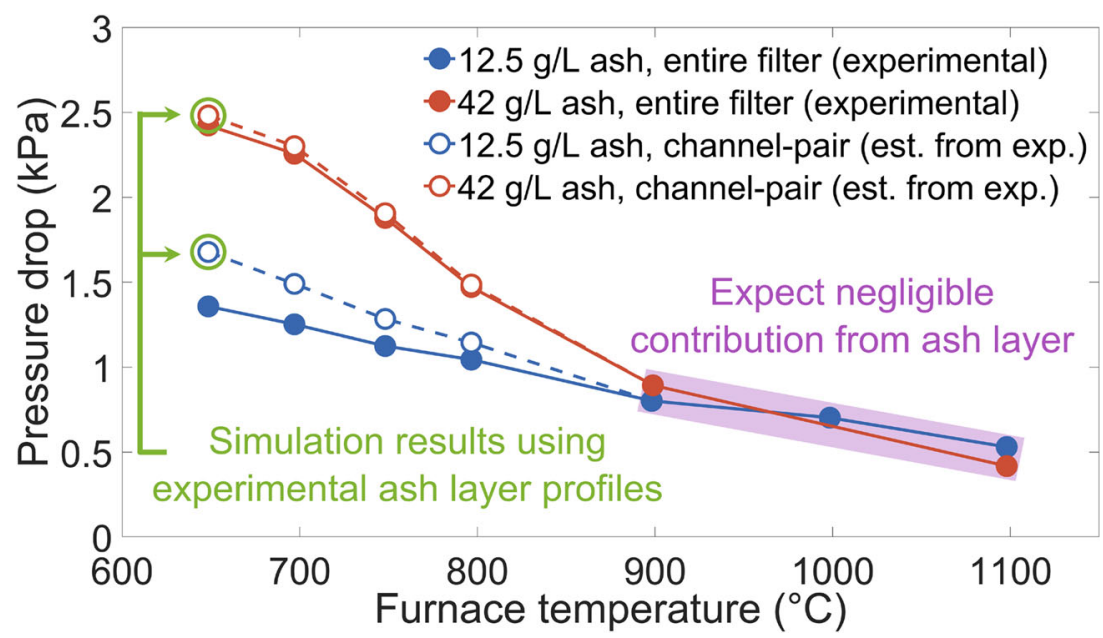




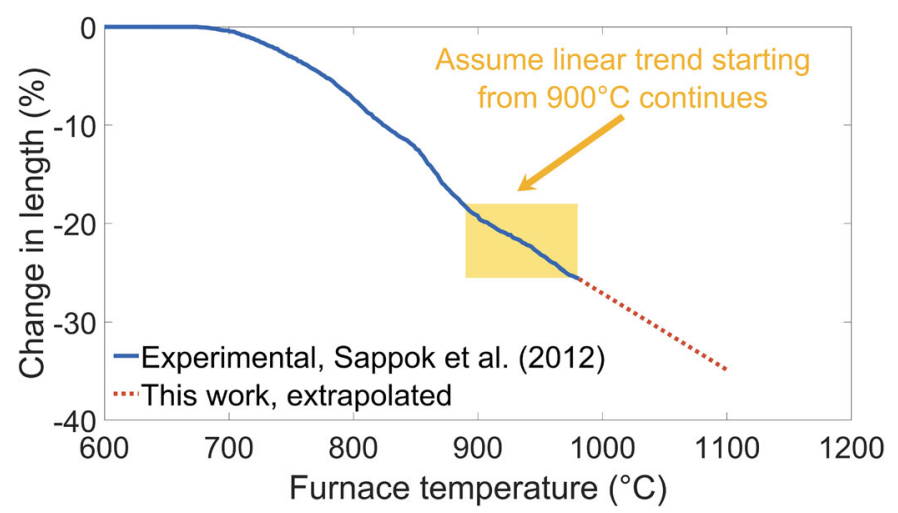

Fig. 14 Experimental data showing dilatometer measurements of the change in the length of ash deposits retrieved from field DPFs versus furnace temperature [36]. These data are used to define the reduction in the bulk volume of the ash deposits induced by the thermal treatment.

the filters studied with the accelerated loading system and from filters installed on vehicles operating in the field. Unfortunately, only the samples from the vehicles in the field produced meaningful dilatometer results, and it is these data that are used here. The data are shown in Fig. 14. The data only extend up to $1000^{\circ} \mathrm{C}$, which is less than the maximum furnace temperature of $1100^{\circ} \mathrm{C}$. The data are therefore extrapolated, assuming that the linear trend observed above $900^{\circ} \mathrm{C}$ continues up to $1100^{\circ} \mathrm{C}$.

Figure 15 shows the results of simulations of thermally treated channel-pairs in the filters with nominal ash loads of $12.5 \mathrm{~g} / \mathrm{L}$ and $42 \mathrm{~g} / \mathrm{L}$. The model shows good agreement with the pressure drop estimated from experimental data when both the sintering and cracking sub-models are enabled. The cracking model parameters were $\alpha=55.33$ and $\beta=0.00266$ for both cases shown in Figs. 15(a) and (b), and control the temperature at which cracking starts to occur in the ash layer. A corresponding sharp decrease in the pressure drop is observed between 700 and $800{ }^{\circ} \mathrm{C}$. The pressure drops continue to decrease for furnace temperatures above $800^{\circ} \mathrm{C}$, albeit at a lower rate. It should be noted that the apparent sharpness of the predicted pressure drop may be an side effect of the model calibration since only three data points were available per filter sample between 700 and $800^{\circ} \mathrm{C}$. More experimental data in this temperature range will be needed to verify whether a gradual or rapid reduction in filter pressure drop occurred.

Additional simulations were performed to investigate the impact of the ash layer. The model predictions with and without the ash layer sub-model enabled (blue solid lines versus yellow dashed lines in Fig. 15) are coincident for furnace temperatures above $800^{\circ} \mathrm{C}$. This indicates that the cracked ash layer makes no contribution to the pressure drop, such that the contribution of the ash to the pressure drop arises from the ash deposits in the wall and the ash plug for furnace temperatures above $800^{\circ} \mathrm{C}$. Comparison of
The volume reduction at high furnace temperatures is extrapolated from the experimental data under the assumption that the apparent linear trend continues

the model predictions without the cracking sub-model and without the ash layer sub-model enabled (red dotted lines versus yellow dashed lines in Fig. 15) shows that the sharp decrease in pressure drop is not observed if crack formation is not considered, and that the difference in the pressure drop between the two cases is nearly independent of the furnace temperature. This implies that sintering has negligible effect on the flow resistance of the ash layer, such that sintering of the ash deposits in the wall and the ash plug is responsible for the decrease in pressure drop above $800^{\circ} \mathrm{C}$.

\subsection{Discussion}

Crack formation in the ash layer is responsible for a significant proportion of the reduction in the pressure drop observed in thermally treated filters. It is highly desirable for crack formation to occur because its full advantage can be achieved without excessive heating, minimising both the energy demand for the thermal treatment and the risk of damaging the filter. Lagemaat et al. [58] suggested that nanoparticle layers with porosity over $75 \%$ would be structurally unstable. Since ash layers typically have porosities greater than $85 \%$ [15], it is likely that crack formation will always occur when the ash layer is thermally treated. Future work should seek to substantiate this and establish the critical conditions for crack formation to occur in the ash layer. In addition, the change of filtration efficiency due to crack formation in the ash layer should be investigated.

Sintering of the ash deposits in the filter walls and the ash plug can further reduce the ash-induced pressure drop after the ash layer has cracked. Since the sintering behaviour of the ash depends on the composition of the lubricant oil, lubricants which leads to ash with low sintering onset temperatures may be favourable, such that a greater reduction in the filter pressure drop can be achieved for 
Fig. 15 Pressure drop of thermally treated filter channel-pairs versus furnace temperature. The soot load for all pressure drop data shown in the figure is $0 \mathrm{~g} / \mathrm{L}$. Good agreement between the model and the pressure drop estimated from experimental data is observed when both sintering and cracking are considered by the model. The cracking of the ash layer causes a rapid decrease in the pressure drop between 700 and $800^{\circ} \mathrm{C}$

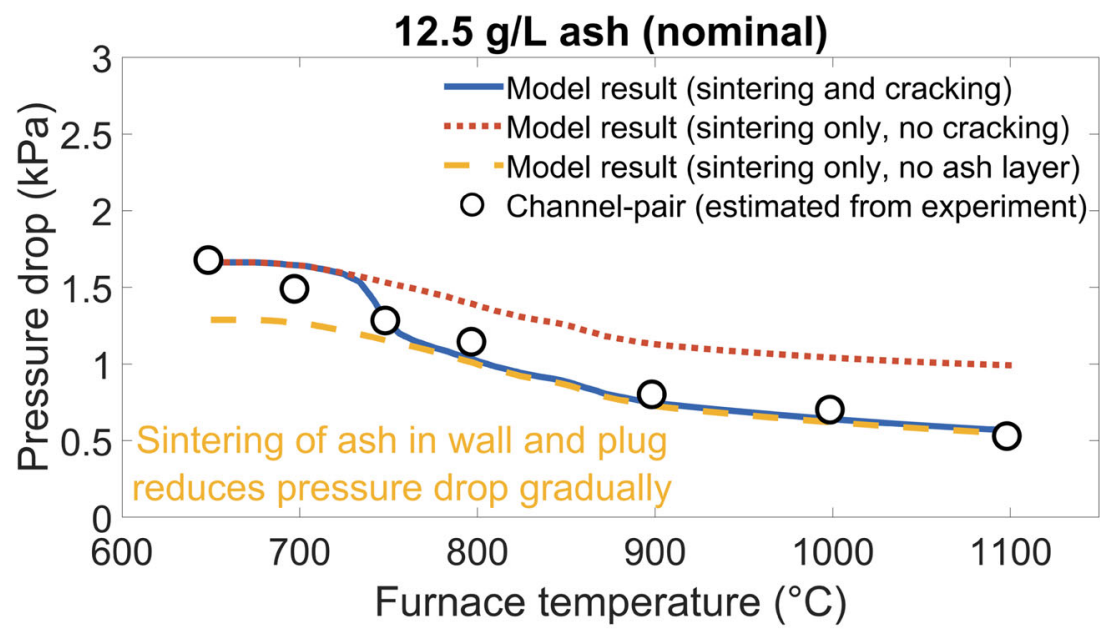

(a) Channel-pair from the filter with $12.5 \mathrm{~g} / \mathrm{L}$ (nominal) ash load.

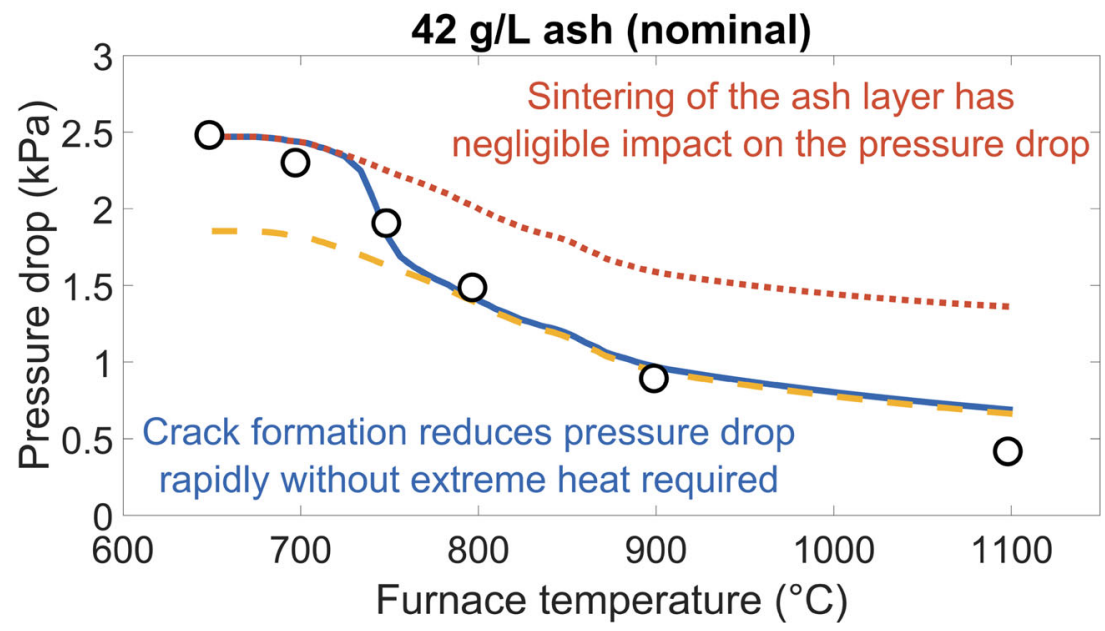

(b) Channel-pair from the filter with $42 \mathrm{~g} / \mathrm{L}$ (nominal) ash load. a given thermal energy input. On the other hand, severely sintered ash deposits may lead to permanent damage to the catalytic washcoat in the filter as well as the integrity of the filter. Good control over the thermal treatment would be required if the ash sintered too easily.

Several aspects of the model merit further scrutiny. The formation of the ash plug was not considered in the simulations of ash loading. An accurate description of the ash plug formation process will likely improve the predictive power of the model. Experimental studies have shown that ash plug is formed by migration of ash deposits down the channel [75]. Sappok et al. [76] observed that ash migration can be induced by either gas flow in the channels or fragmentation of the soot cake layer. Furthermore, the adhesivenesses between ash, soot and filter wall substrate have significant impact on the ash migration process [77]. Currently only a few modelling studies are available in the literature that have attempted to simulate the ash plug formation process $[76,78]$. Future work should investigate how soot-ash affinity may be affected by the composition of soot and ash. A deeper understanding of ash migration will benefit the development of ash management strategies.

In this work, the impact of active regeneration was post-processed assuming that the ash layer had a uniform microstructure. In practice, the local porosity and permeability of the ash layer can vary significantly in the axial direction due to local hot-spots in the soot cake layer and the ash layer during active regenerations $[65,79]$. Consideration of the in-homogeneity of the ash layer, in combination of an accurate ash migration model, can greatly improve the predictability of the model.

Experimental data show considerable channel-to-channel variation in ash layer profiles [65]. Whilst a multi-channel model may be able to capture the variations between channels, the development of such a model requires a good understanding of phenomena occurring within each individual channel. Future experiments may consider using a downsized filter with fewer channels to limit the 
variation in measurements across different channels. This would support the development of more accurate singlechannel models and aid the development of multi-channel models.

Information about the change in the bulk volume of ash deposits is critical as substantiated in Section 3.3. In this work, measurements made using a dilatometer were used to describe the change in bulk volume of the ash deposits as a function of the temperature of the thermal treatment. Although this led to good agreement between the simulation results and experimental data, a dilatometer requires ash samples to be removed from the filter before testing. This risks altering the properties of the ash deposits and increases the uncertainty of the dilatometer results because the sintering behaviour depends on the initial morphology of the ash deposits [80]. Furthermore, Sappok et al. [36] observed that ash deposits sinter inwards and away from the filter wall. This can have an impact of the flow resistance of the ash layer and the filter wall but movement of ash deposits is not considered by the model used in this work. The sintering behaviour of ash deposits may be better understood if measurements by X-ray chromatography [81] or Magnetic Resonance Imaging [82] were available. The application of non-destructive imaging techniques would eliminate the uncertainty introduced by removing ash from the filter.

\section{Conclusions}

A particulate filter model has been developed to simulate the change in the behaviour of ash-contaminated particulate filters when the filters are thermally treated by exposing them to high temperatures. The model was calibrated using experimental data for a clean filter, followed by data for a soot-loaded filter. The model was applied to simulate the accumulation of ash in the filter in order to estimate the spatial distribution of the ash deposits within the filter wall and the diameter of the particles in the ash layer. Finally, the impact of heat-induced sintering and cracking of the ash deposits was examined using the model.

The model suggests that crack formation in the ash layer leads to significant reduction of the pressure drop at relatively low temperatures. Most of the benefits due to crack formation were attained using a treatment temperature of $800^{\circ} \mathrm{C}$. The ash-induced pressure drops of the lightly loaded and the heavily loaded filters were reduced by $38 \%$ and $48 \%$ respectively at this treatment temperature. Further reduction of the pressure drop at higher temperatures is controlled by the sintering of ash deposits within the porous wall of the filter and the ash plug.

The model has been shown to be capable of predicting the pressure drop of ash-loaded filters when the bulk volume of the ash deposits is known. The accuracy of the model prediction for thermally treated filters relies heavily on accurate measurements of the change in the bulk volume of the ash deposits.

In this work it is shown that crack formation in the ash layer is critical to reduce the pressure drop across the filter. Therefore it is crucial to guarantee crack formation during the thermal treatment. Further work is required to determine in more detail the operating conditions and ash properties that induce crack formation.

\section{Appendix A. Derivation of the sintering model}

This section describes the derivation of Eq. (31)

$\epsilon_{\mathrm{ash}}=1-\frac{1-\epsilon_{\mathrm{ash} 0}}{d_{\mathrm{ash} 0}^{2}} d_{\mathrm{ash}}^{2}$,

which relates the porosity of the ash layer $\epsilon_{\text {ash }}$ to the size of the ash particles $d_{\text {ash }}$.

The sintering model approximates the ash layer as columns of equally sized particles as shown in Fig. 16. It is assumed that the particles merge as sintering proceeds, until they eventually form a mono-layer of particles in point contact. The mono-layer is the maximum extent of the sintering that can be considered by this analogy. This state is denoted by the subscript "final" in the following equations. The initial state where sintering has not occurred is denoted by the subscript " 0 ". The porosity of the mono-layer $\epsilon_{\text {final }}$ is independent of the size of the particles

$\epsilon_{\text {final }}=1-\frac{\frac{\pi}{6} d_{\mathrm{p}, \text { final }}^{3}}{d_{\mathrm{p}, \text { final }}^{3}}=1-\frac{\pi}{6}$,

\section{Side view}

\section{Top view}
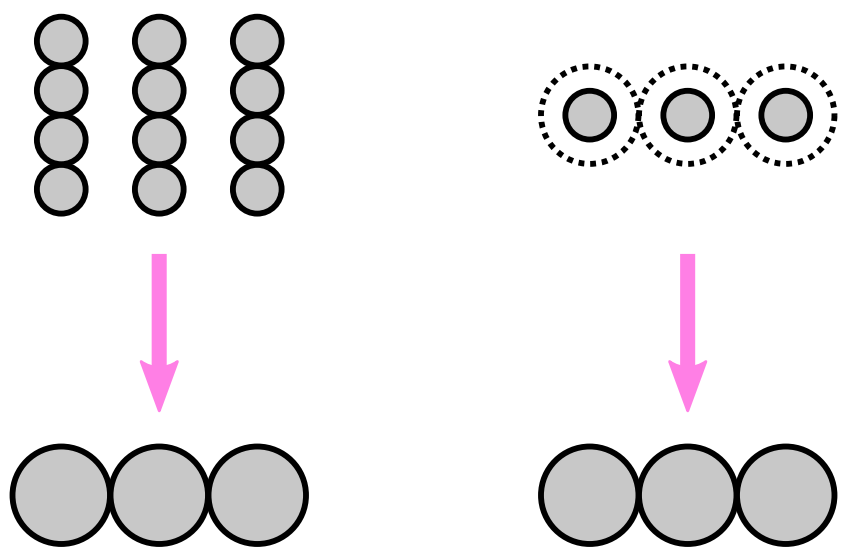

Fig. 16 Side view and top view of the particle columns representing the ash layer in the sintering model 
where $d_{\mathrm{p} \text {,final }}$ is the final particle diameter. The initial particle diameter $d_{\mathrm{p} 0}$ can be calculated based on conservation of the volume of the ash

$d_{\mathrm{p} 0}=d_{\mathrm{p}, \text { final }} n_{\mathrm{p} 0}^{-\frac{1}{3}}$

where $n_{\mathrm{p} 0}$ is the initial number of particles in a column.

The initial porosity $\epsilon_{0}$ can be derived by considering the particle columns from top view shown in Fig. 16. The porosity of the particle columns scales proportionally with the cross-section area occupied by the ash particles. As a result, $\epsilon_{0}$ can be expressed as

$\epsilon_{0}=1-\frac{\pi}{6} \frac{d_{\mathrm{p} 0}^{2}}{d_{\mathrm{p}, \text { final }}^{2}}=1-\frac{\pi}{6} n_{\mathrm{p} 0}^{-\frac{2}{3}}$.

The following general equation is assumed to describe intermediate levels of sintering

$\epsilon=1-\frac{\pi}{6} \frac{d_{\mathrm{p}}^{2}}{d_{\mathrm{p}, \text { final }}^{2}}=1-\frac{\pi}{6} \frac{1}{d_{\mathrm{p} 0}^{2} n_{\mathrm{p} 0}^{\frac{2}{3}}} d_{\mathrm{p}}^{2}$.

An expression of $n_{\mathrm{p} 0}$ can be found by rearranging Eq. (A.3)

$n_{\mathrm{p} 0}^{\frac{2}{3}}=\frac{\pi}{6} \frac{1}{1-\epsilon_{0}}$

Equation (31) can be derived from Eq. (A.4) by substituting Eq. (A.5)

$\epsilon_{\mathrm{ash}}=1-\frac{1-\epsilon_{\mathrm{ash} 0}}{d_{\mathrm{ash} 0}^{2}} d_{\mathrm{ash}}^{2}$

\section{Appendix B. Axial distribution of ash deposits within the wall}

Figure 17 shows the amount of ash accumulated within the filter wall during the first four ash accumulation cycles of the simulations discussed in Section 3.2.3. It can be observed that the ash deposition in the wall is practically uniform in the axial direction for every cycle. The maximum deviation between the volume element with the highest ash load and that with the lowest ash load is $0.9 \%$ after the first cycle. This deviation decreases as more cycles are executed. The maximum deviation after four cycles is $0.6 \%$. This substantiates the assumption in the sintering model for the ash plug (see Section 2.4.1) that the axial variation of the ash deposits in the wall is negligible.

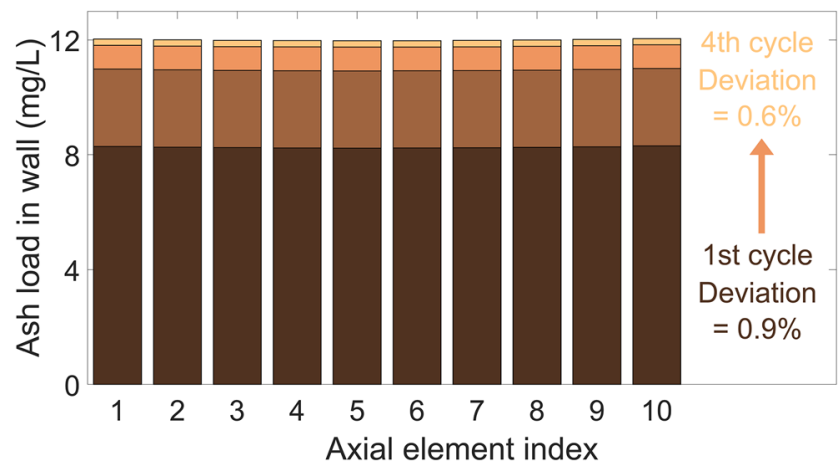

Fig. 17 Ash load accumulated in the porous wall over the first four ash accumulation cycles. The ash deposit distribution is practically uniform. The uniformity increases with increased ash accumulation

\section{Nomenclature}

\section{Upper-case Roman}

\begin{tabular}{lll}
\hline Symbol & Definition & Unit \\
\hline$A, B$ & Cracking model parameter (literature) & - \\
$C$ & Stoke-Cunningham factor & - \\
$D$ & Channel side length & $\mathrm{m}$ \\
$D_{f}$ & Fractal dimension & - \\
$E$ & Type space & - \\
$F$ & Friction factor & - \\
$\mathrm{Kn}$ & Knudsen number & - \\
$L$ & Length & $\mathrm{m}$ \\
$N$ & Particle number density & $1 / \mathrm{m}^{3}$ \\
$N_{\text {cord }}$ & Coordination number & - \\
$N$ & Particle number density flow rate & $1 / \mathrm{m}^{3} \mathrm{~s}$ \\
$P$ & Pressure & $\mathrm{Pa}$ \\
$\mathrm{Pe}$ & Peclet number & - \\
$Q$ & Filtration efficiency & - \\
$R$ & Interception parameter & - \\
$S$ & Index set & - \\
$V$ & Volume & $\mathrm{m}^{3}$ \\
$V_{f}$ & Volume filling factor & - \\
$X$ & Progress variable for sintering & - \\
\hline
\end{tabular}

\section{Lower-case Roman}

\begin{tabular}{lll}
\hline Symbol & Definition & Unit \\
\hline$d$ & Diameter & $\mathrm{m}$ \\
$f$ & Kuwabara geometric function & - \\
$g$ & Kuwabara geometric function & - \\
$i, j$ & Index of volume element & - \\
$m$ & Mass & $\mathrm{kg}$ \\
$n$ & Number of particles & - \\
$n_{\mathrm{ax}}$ & Number of axial discretisation & - \\
$n_{\mathrm{w}}$ & Number of through-wall discretisation & - \\
$t$ & Time & $\mathrm{s}$ \\
$u, v$ & Velocity & $\mathrm{m} / \mathrm{s}$ \\
$w$ & Thickness & $\mathrm{m}$ \\
$z$ & Index of particle size class & - \\
\hline
\end{tabular}




\section{Greek}

\begin{tabular}{lll}
\hline Symbol & Definition & Unit \\
\hline$\alpha, \beta, \gamma, \theta$ & Cracking model parameter & - \\
$\epsilon$ & Porosity & - \\
$\eta$ & Single collector efficiency & - \\
$\kappa$ & Permeability & $\mathrm{m}^{2}$ \\
$\mu$ & Dynamic viscosity & $\mathrm{Pa} \mathrm{s}$ \\
$\rho$ & Mass density & $\mathrm{kg} / \mathrm{m}^{3}$ \\
$\rho_{\mathrm{w}}$ & Particle packing density in filter wall & $\mathrm{kg} / \mathrm{m}^{3}$ \\
$\psi$ & Percolation constant & - \\
$\Phi$ & Partition coefficient & - \\
\hline
\end{tabular}

\section{Subscripts}

\begin{tabular}{ll}
\hline Symbol & Definition \\
\hline agg & Aggregate \\
ash & Ash \\
cake & Soot cake \\
c & Denotes the cracking sub-model \\
ci & Inlet channel \\
co & Outlet channel \\
coll & Collector \\
D & Denotes diffusional filtration \\
d & Denotes damaged layer \\
frac & Denotes fractal diameter \\
mob & Denotes mobility diameter \\
p & Particle \\
plug & Ash plug \\
pm & Porous media \\
pore & Pore \\
pri & Primary particle \\
R & Denotes interceptional filtration \\
s & Denotes the sintering sub-model \\
w & Denotes parameters in the filter wall \\
0 & Denotes an initial condition \\
\hline
\end{tabular}

\section{Abbreviations}

\begin{tabular}{ll}
\hline Symbol & Definition \\
\hline ACT & Asymmetric channel technology \\
DPF & Diesel particulate filter \\
GDI & Gasoline direct injection \\
GPF & Gasoline particulate filter \\
ICE & Internal combustion engine \\
PM & Particulate matter \\
PN & Particle number \\
WFM & Wall flow monolith \\
XRT & X-ray tomography \\
\hline
\end{tabular}

Acknowledgements The authors would like to thank Royal Dutch Shell for their support.

Funding This research was supported by the National Research Foundation, Prime Minister's Office, Singapore, under its Campus for Research Excellence and Technological Enterprise (CREATE) programme. CMCL Innovations is grateful to the European Commission for funding part of the research via the European Union, Horizon 2020 Programme, SimDome Project, Grant Agreement No. 814492. This work was supported by the UK Engineering and Physical Sciences Research Council (EPSRC) grant 1622599.

Research Data Research data supporting this publication is available in the University of Cambridge data repository (10.17863/CAM.56872).

Compliance with ethical standards The authors declare that they have no competing interests.

Open Access This article is licensed under a Creative Commons Attribution 4.0 International License, which permits use, sharing, adaptation, distribution and reproduction in any medium or format, as long as you give appropriate credit to the original author(s) and the source, provide a link to the Creative Commons licence, and indicate if changes were made. The images or other third party material in this article are included in the article's Creative Commons licence, unless indicated otherwise in a credit line to the material. If material is not included in the article's Creative Commons licence and your intended use is not permitted by statutory regulation or exceeds the permitted use, you will need to obtain permission directly from the copyright holder. To view a copy of this licence, visit http://creativecommons. org/licenses/by/4.0/.

\section{References}

1. Hopke, P.K., Dai, Q., Li, L., Feng, Y.: Global review of recent source apportionments for airborne particulate matter. Sci. Total Environ. 740, 140091 (2020). https://doi.org/10.1016/j.scitotenv. 2020.140091

2. Lelieveld, J., Evans, J.S., Fnais, M., Giannadaki, D., Pozzer, A.: The contribution of outdoor air pollution sources to premature mortality on a global scale. Nature 525, 367-371 (2015). https://doi.org/10.1038/nature15371

3. Ramanathan, V., Carmichael, G.: Global and regional climate changes due to black carbon. Nat. Geosci. 1, 221-227 (2008). https://doi.org/10.1038/ngeo156

4. Beatrice, C., Rispoli, N., Di Blasio, G., Konstandopoulos, A.G., Papaioannou, E., Imren, A.: Impact of emerging engine and after-treatment technologies for improved fuel efficiency and emission reduction for the future rail diesel engines. Emiss. Control Sci. Technol. 2, 99-112 (2016). https://doi.org/10.1007/s40825-016-0035-1

5. Giechaskiel, B., Joshi, A., Ntziachristos, L., Dilara, P.: European regulatory framework and particulate matter emissions of gasoline light-duty vehicles: a review. Catalysts 9(7), 586 (2019). https://doi.org/10.3390/cata19070586

6. Pavlovic, J., Ciuffo, B., Fontaras, G., Valverde, V., Marotta, A.: How much difference in type-approval $\mathrm{CO}_{2}$, emissions from passenger cars in europe can be expected from changing to the new test procedure (NEDC vs WLTP)? Transp. Res. Part A: Policy Pract. 111, 136-147 (2018). https://doi.org/10.1016/j.tra.2018.02.002

7. Bishop, J.D.K., Molden, N., Boies, A.M.: Using portable emissions measurement systems (pems) to derive more accurate estimates of fuel use and nitrogen oxides emissions from modern euro 6 passenger cars under real-world driving conditions. Appl. Energy 242, 942-973 (2019). https://doi.org/10.1016/j.apenergy.2019.03.047

8. Konstandopoulos, A.G., Kostoglou, M., Vlachos, N., Kladopoulou, E.: Progress in diesel particulate filter simulation. 
In: SAE 2005 World Congress \& Exhibition. SAE International, Apr 2005. https://doi.org/10.4271/2005-01-0946 (2005)

9. Mamakos, A., Steininger, N., Martini, G., Dilara, P., Drossinos, Y.: Cost effectiveness of particulate filter installation on direct injection gasoline vehicles. Atmos. Environ. 77, 16-23 (2013). https://doi.org/10.1016/j.atmosenv.2013.04.063

10. Demuynck, J., Favre, C., Bosteels, D., Hamje, H., Andersson, J.: Real-world emissions measurements of a gasoline direct injection vehicle without and with a gasoline particulate filter. In: SAE Technical Paper. SAE International. https://doi.org/10.4271/2017-01-0985 (2017)

11. Joshi, A., Johnson, T.V.: Gasoline particulate filters - a review. Emission Control Science and Technology 4, 219-239 (2018). https://doi.org/10.1007/s40825-018-0101-y

12. Bagi, S., Bowker, R., Andrew, R.: Understanding chemical composition and phase transitions of ash from field returned dpf units and their correlation with filter operating conditions. SAE Int. J. Fuels Lubr. 9, 239-259 (2016). https://doi.org/10.4271/2016-01-0898

13. Bernardoff, R., Hennebert, B., Delvigne, T., Courtois, O., China, P.: A study of ash accumulation in the after-treatment system of a gasoline direct injection engine equipped with a gasoline particulate filter. In: WCX 17: SAE World Congress Experience. SAE International. https://doi.org/10.4271/2017-01-0879 (2017)

14. Wang, H., Ge, Y., Tan, J., Hao, L., Wu, L., Yang, J., Du, Q., Zhang, H., Huang, Y., Chen, Y., Li, X., Peng, Z.: Ash deposited in diesel particular filter: a review. Energy Sources Part A: Recovery Util. Environ. Eff. 41(18), 2184-2193 (2019). https://doi.org/10.1080/15567036.2018.1550539

15. Wang, Y., Kamp, C.J., Wang, Y., Toops, T.J., Changsheng, S., Wang, R., Gong, J., Wong, V.W.: The origin, transport, and evolution of ash in engine particulate filters. Appl. Energy 263(February), 114631 (2020). https://doi.org/10.1016/j. apenergy.2020.114631

16. Lambert, CK., Chanko, T., Jagner, M., Hangas, J., Liu, X., Pakko, J., Kamp, C.J.: Analysis of ash in low mileage, rapid aged, and high mileage gasoline exhaust particle filters. SAE Int. J. Engines 10, 1595-1603 (2017). https://doi.org/10.4271/2017-01-0930

17. Dittler, A.: Ash transport in diesel particle filters. In: SAE 2012 International powertrains, fuels \& lubricants meeting, SAE International. https://doi.org/10.4271/2012-01-1732 (2012)

18. Kittelson, D.B.: Engines and nanoparticles: a review. J. Aerosol Sci. 29(5), 575-588 (1998). https://doi.org/10.1016/S0021-8502 (97)10037-4

19. Kittelson, D., Kraft, M.: Particle formation and models. American Cancer Society 1-23. https://doi.org/10.1002/9781118354179. auto161 (2014)

20. Eakle, S., Avery, S., Weber, P., Henry, C.: Comparison of accelerated ash loading methods for gasoline particulate filters. In: International Powertrains, Fuels \& Lubricants Meeting. SAE International. https://doi.org/10.4271/2018-01-1703 (2018)

21. Shao, H., Lam, W., Remias, J., Roos, J., Choi, S., Seong, H.: Effect of lubricant oil properties on the performance of gasoline particulate filter (GPF). SAE Int. J. Fuels Lubr. 9, 650-658 (2016). https://doi.org/10.4271/2016-01-2287

22. Lee, K.F., Eaves, N., Mosbach, S., Ooi, D., Lai, J., Bhave, A., Manz, A., Geiler, J.N., Noble, J.A., Duca, D., Focsa, C.: Model guided application for investigating particle number (PN) emissions in GDI spark ignition engines, vol. 1. https://doi.org/10.4271/2019-26-0062 (2019)

23. Ishizawa, T., Yamane, H., Satoh, H., Sekiguchi, K., Arai, M., Yoshimoto, N., Inoue, T.: Investigation into ash loading and its relationship to DPF regeneration method. SAE Int. J. Commer. Veh. 2, 164-175 (2009). https://doi.org/10.4271/2009-01-2882
24. Zarvalis, D., Lorentzou, S., Konstandopoulos, A.G.: A methodology for the fast evaluation of the effect of ash aging on the diesel particulate filter performance. In: SAE World Congress \& Exhibition. SAE International. https://doi.org/10.4271/2009-01-0630 (2009)

25. Liu, X., Chanko, T., Lambert, C., Maricq, M.: Gasoline particulate filter efficiency and backpressure at very low mileage. In: WCX World Congress Experience. SAE International. https://doi.org/10.4271/2018-01-1259 (2018)

26. Morcos, M., Ayyappan, P., Harris, T.: Characterization of DPF ash for development of DPF regeneration control and ash cleaning requirements. In: SAE 2011 World Congress \& Exhibition, SAE International. https://doi.org/10.4271/2011-01-1248 (2011)

27. Chen, T., Zhixin, W., Gong, J., Jiaqiang, E.: Numerical simulation of diesel particulate filter regeneration considering ash deposit. Flow Turbul. Combust. 97, 849-864 (2016). https://doi.org/10.1007/s10494-016-9717-6

28. Deng, Y., Cui, J., Jiaqiang, E., Zhang, B., Zhao, X., Zhang, Z., Han, D.: Investigations on the temperature distribution of the diesel particulate filter in the thermal regeneration process and its field synergy analysis. Appl. Therm. Eng. 123, 92-102 (2017). https://doi.org/10.1016/j.applthermaleng.2017.05.072

29. Wurzenberger, J.C., Kutschi, S., Nikodem, A.: Ash transport and deposition, cake formation and segregation-a modeling study on the impact of ash on particulate filter performance. In: WCX SAE World Congress Experience. SAE International. https://doi.org/10.4271/2019-01-0988 (2019)

30. Twigg, M.V.: Catalytic control of emissions from cars. Catal. Today 163(1), 33-41 (2011). Special issue on Industrial Catalysis. https://doi.org/10.1016/j.cattod.2010.12.044

31. Lambert, C., Chanko, T., Dobson, D., Liu, X., Pakko, J.: Gasoline particle filter development. Emiss. Control Sci. Technol 3, 105111 (2017). https://doi.org/10.1007/s40825-016-0055-X

32. Young, D.M., Hickman, D.L., Bhatia, G., Gunasekaran, N.: Ash storage concept for diesel particulate filters. In: SAE World Congress \& Exhibition, SAE International. https://doi.org/10.4271/2004-01-0948, p. 2004 (2004)

33. Wang, W., Bissett, E.J.: Frictional and heat transfer characteristics of flow in triangle and hexagon channels of Wall-Flow monoliths. Emiss. Control Sci. Technol. 4, 198-218 (2018). https://doi.org/10.1007/s40825-018-0093-7

34. Sappok, A., Santiago, M., Vianna, T., Wong, V.W.: Characteristics and effects of ash accumulation on diesel particulate filter performance: Rapidly aged and field aged results. In: SAE World Congress \& Exhibition. SAE International . https://doi.org/10.4271/2009-01-1086 (2009)

35. Sappok, A., Rodriguez, R., Wong, V.: Characteristics and effects of lubricant additive chemistry on ash properties impacting diesel particulate filter service life. SAE Int. J Fuels Lubr. 3, 705-722 (2010). https://doi.org/10.4271/2010-01-1213

36. Sappok, A., Kamp, C., Wong, V.: Sensitivity analysis of ash packing and distribution in diesel particulate filters to transient changes in exhaust conditions. SAE Int. J. Fuels Lubr. 5(2), 733-750 (2012). ISSN 19463960. https://doi.org/10.4271/2012-01-1093

37. Sappok, A., Munnis, S., Wong, V.W.: Individual and synergistic effects of lubricant additive components on diesel particulate filter ash accumulation and performance. In: Proceedings of the ASME 2012 Internal Combustion Engine Division Spring Technical Conference, pp 531-546 (2012)

38. Lao, C.T., Akroyd, J., Eaves, N., Smith, A., Morgan, N., Bhave, A., Kraft, M.: Modelling particle mass and particle number emissions during the active regeneration of diesel particulate filters. Proc. Combust. Inst. 37(4), 4831-4838 (2019). https://doi.org/10.1016/j.proci.2018.07.079 
39. Lao, C.T., Akroyd, J., Eaves, N., Smith, A., Morgan, N., Nurkowski, D., Bhave, A., Kraft, M.: Investigation of the impact of the configuration of exhaust after-treatment system for diesel engines. Appl. Energy 267(mar), 114844 (2020). https://doi.org/10.1016/j.apenergy.2020.114844

40. Hayashi, H., Kubo, S.: Computer simulation study on filtration of soot particles in diesel particulate filter. Comput. Math. Appl. 55(7), 1450-1460 (2008). https://doi.org/10.1016/j.camwa.2007.08.012

41. Matyáš, S., Miloš, M., Kubíček, M., Kočí, P.: Modelling of diesel filters for particulates removal. Chem. Eng. J. 154(1-3), 219-230 (2009). https://doi.org/10.1016/j.cej.2009.04.056

42. Sorensen, C.M.: The mobility of fractal aggregates: a review. Aerosol Sci. Tech. 45(7), 755-769 (2011). https://doi.org/10.1080/02786826.2011.560909

43. Park, S.H., Rogak, S.N., Bushe, W.K., Wen, J.Z., Thomson, M.J.: An aerosol model to predict size and structure of soot particles. Combustion Theory Model. 9(3), 499-513 (2005). https://doi.org/10.1080/13647830500195005

44. Zhang, Q., Thomson, M.J., Guo, H., Liu, F., Smallwood, G.J.: Modeling of Oxidation-Driven soot aggregate fragmentation in a laminar coflow diffusion flame. Combust. Sci. Technol. 182(4-6), 491-504 (2010). https://doi.org/10.1080/00102200903463050

45. Eaves, N.A., Zhang, Q., Liu, F., Guo, H., Dworkin, S.B., Thomson, M.J.: Coflame: A refined and validated numerical algorithm for modeling sooting laminar coflow diffusion flames. Comput. Phys. Commun. 207, 464-477 (2016). https://doi.org/10.1016/j.cpc.2016.06.016

46. Duvvuri, P.P., Sukumaran, S., Shrivastava, R.K., Sreedhara, S.: Modeling soot particle size distribution in diesel engines. Fuel 243, 70-78 (2019). https://doi.org/10.1016/j.fuel.2019.01.104

47. Lee, K.W., Gieseke, J.A.: Collection of aerosol particles by packed beds. Environ. Sci. Technol. 13(4), 466-470 (1979). https://doi.org/10.1021/es60152a013

48. Konstandopoulos, A.G., Kostoglou, M., Skaperdas, E., Papaioannou, E., Zarvalis, D., Kladopoulou, E.: Fundamental studies of diesel particulate filters: Transient loading, regeneration and aging. In: SAE 2000 World Congress. SAE International. https://doi.org/10.4271/2000-01-1016 (2000)

49. Payri, F., Broatch, A., Serrano, J.R., Piqueras, P.: Experimentaltheoretical methodology for determination of inertial pressure drop distribution and pore structure properties in wall-flow diesel particulate filters (DPFs). Energy 36(12), 6731-6744 (2011). https://doi.org/10.1016/j.energy.2011.10.033

50. Sorensen, C.M., Roberts, G.C.: The prefactor of fractal aggregates. J. Colloid Interface Sci. 186(2), 447-452 (1997). https://doi.org/10.1006/jcis.1996.4664

51. Barry, A.A.L., Setten, V., Makkee, M., Moulijn, J.A.: Science and technology of catalytic diesel particulate filters. Catal. Rev. 43(4), 489-564 (2001). https://doi.org/10.1081/CR-120001810

52. Kladopoulou, E.A., Yang, S.L., Johnson, J.H., Parker, G.G., Konstandopoulos, A.G.: A study describing the performance of diesel particulate filters during loading and regeneration - a lumped parameter model for control applications. In: SAE World Congress \& Exhibition, SAE International. https://doi.org/10.4271/2003-01-0842, p. 2003 (2003)

53. Lee, K.W., Reed, L.D., Gieseke, J.A.: Pressure drop across packed beds in the low Knudsen number regime. J. Aerosol Sci. 9(6), 557-565 (1978). https://doi.org/10.1016/0021-8502(78)90021-6

54. Konstandopoulos, A.G., Skaperdas, E., Masoudi, M.: Microstructural properties of soot deposits in diesel particulate traps. In: SAE 2002 World Congress and Exhibition, SAE International. https://doi.org/10.4271/2002-01-1015 (2002)

55. Sappok, A.G., Beauboeuf, D., Wong, V.W.: A novel accelerated aging system to study lubricant additive effects on diesel aftertreatment system degradation. SAE Int. J Fuels Lubr. 1, 813-827 (2009). https://doi.org/10.4271/2008-01-1549

56. Chen, K., Luss, D.: Temperature excursions in diesel particulate filters: Response to shift to idle. Ind. Eng. Chem. Res. 50(2), 832-842 (2011). https://doi.org/10.1021/ie101844r

57. Yamamoto, K., Kondo, S., Suzuki, K.: Filtration and regeneration performances of sic fiber potentially applied to gasoline particulates. Fuel 243, 28-33 (2019). https://doi.org/10.1016/j.fuel.2019. 01.099

58. Lagemaat, J., Benkstein, K.D., Frank, A.J.: Relation between particle coordination number and porosity in nanoparticle films: Implications to dye-sensitized solar cells. J. Phys. Chem. B 105(50), 12433-12436 (2001). https://doi.org/10.1021/jp013369z

59. Houi, D., Lenormand, R.: Particle deposition on a filter medium. In: Kinetics of Aggregation and Gelation, pp. 173-176. Elsevier (1984). https://doi.org/10.1016/B978-0-444-86912-8.50041-9

60. Thomas, D., Ouf, F.X., Gensdarmes, F., Bourrous, S., Bouilloux, L.: Pressure drop model for nanostructured deposits. Sep. Purif. Technol. 138, 144-152 (2014). https://doi.org/10.1016/j.seppur.2014.09.032

61. Mahadevan, B.S., Johnson, J.H., Shahbakhti, M.: Predicting pressure drop, temperature, and particulate matter distribution of a catalyzed diesel particulate filter using a multi-zone model including cake permeability. Emiss. Control Sci. Technol. 3(2), 171-201 (2017). https://doi.org/10.1007/s40825-017-0062-6

62. Picandet, V., Khelidj, A., Bastian, G.: Effect of axial compressive damage on gas permeability of ordinary and highperformance concrete. Cem. Concr. Res. 31(11), 1525-1532 (2001). https://doi.org/10.1016/S0008-8846(01)00546-4

63. Pijaudier-Cabot, G., Dufour, F., Choinska, M.: Permeability due to the increase of damage in concrete: from diffuse to localized damage distributions. J. Eng. Mech. 135(9), 1022-1028 (2009). https://doi.org/10.1061/(ASCE)EM.1943-7889.0000016

64. Selvadurai, A.P.S., Boulon, M.J., Nguyen, T.S.: The permeability of an intact granite. Pure Appl. Geophys. 162, 373-407 (2005). https://doi.org/10.1007/s00024-004-2606-2

65. Alexander, S.: The nature of lubricant-derived ash-related emissions and their impact on diesel aftertreatment system performance. PhD thesis, Massachusetts Institue of Technology (2009)

66. Konstandopoulos, A.G., Skaperdas, E., Masoudi, M.: Inertial contributions to the pressure drop of diesel particulate filters. In: SAE World Congress. SAE International. https://doi.org/10.4271/2001-01-0909, p. 2001 (2001)

67. Tronconi, E., Nova, I., maritti, F., Koltsakis, G., Karamitros, D., Maletic, B., Markert, N., Chatterjee, D., Hehle, M.: Interaction of $\mathrm{NO}_{\mathrm{x}}$ reduction and soot oxidation in a DPF with $\mathrm{Cu}$-Zeolite SCR coating. Emission Control Sci. Technol. 1, 134-151 (2015). https://doi.org/10.1007/s40825-015-0014-y

68. Rumpf, H.C.H., Gupte, A.R.: Einflüsse der porosität und korngrößenverteilung im Widerstandsgesetz der porenströmung. Chemie Ingenieur Technik 43(6), 367-375 (1971). https://doi.org/10.1002/cite.330430610

69. Seong, H., Choi, S., Matusik, K.E., Kastengren, A.L., Powell, C.F.: 3D pore analysis of gasoline particulate filters using X-ray tomography: impact of coating and ash loading. J. Mater. Sci. 54, 6053-6065 (2019). https://doi.org/10.1007/s10853-018-03310-w

70. Zhang, Z., Yang, S.L., Johnson, J.H.: Modeling and numerical simulation of diesel particulate trap performance during loading and regeneration. In: SAE World Congress \& Exhibition, SAE International. https://doi.org/10.4271/2002-01-1019, p. 2002 (2002)

71. Lupše, J., Campolo, M., Soldati, A.: Modelling soot deposition and monolith regeneration for optimal design of automotive DPFs. Chem. Eng. Sci. 151, 36-50 (2016). https://doi.org/10.1016/j.ces.2016.05.008 
72. Liu, J., Swanson, J.J., Kittelson, D.B., Pui, D.Y.H., Wang, J.: Microstructural and loading characteristics of diesel aggregate cakes. Powder Technol. 241, 244-251 (2013). https://doi.org/10.1016/j.powtec.2013.03.028

73. Gong, J., Viswanathan, S., Rothamer, D.A., Foster, D.E., Rutland, C.J.: Dynamic heterogeneous multiscale filtration model: Probing micro- and macroscopic filtration characteristics of gasoline particulate filters. Environ. Sci. Technol. 51(19), 11196-11204 (2017). https://doi.org/10.1021/acs.est.7b02535

74. Park, K., Kittelson, D.B., Zachariah, M.R., McMurry, P.H.: Measurement of inherent material density of nanoparticle agglomerates, vol. 6, pp. 267-272 (2004). https://doi.org/10.1023/ B:NANO.0000034657.71309.e6

75. Matsuno, M., Kitamura, T.: Direct visualization of soot and ash transport in diesel particulate filters during active regeneration process. In: 2019 JSAE/SAE Powertrains, Fuels and Lubricants, SAE International. https://doi.org/10.4271/2019-01-2287, p. 2019 (2019)

76. Sappok, A., Wang, Y., Wang, R.-Q., Kamp, C., Wong, V.: Theoretical and experimental analysis of ash accumulation and mobility in ceramic exhaust particulate filters and potential for improved ash management. SAE Int. J Fuels Lubr. 7, 511-524 (2014)

77. Kamp, C.J., Sappok, A., Wang, Y., Bryk, W., Rubin, A., Wong, V.: Direct measurements of soot/ash affinity in the diesel particulate filter by atomic force microscopy and implications for ash accumulation and dpf degradation. SAE Int. J. Fuels Lubr. 7, 307-316 (2014)
78. Koltsakis, G., Mitsouridis, M., Mylonidis, I., Baumgard, K., Duddukuri, R., Zhou, W., George, S., Viswanathan, S., Heibel, A.: Towards predictive ash accumulation and transport modeling Presented at CLEERS 2020 on 15/09/2020. https://cleers.org/ cleers-workshops/workshop-presentations/entry/2755/ (2020)

79. Kostoglou, M., Housiada, P., Konstandopoulos, A.G.: Multichannel simulation of regeneration in honeycomb monolithic diesel particulate filters. Chem. Eng. Sci. 58(14), 3273-3283 (2003). https://doi.org/10.1016/S0009-2509(03)00178-7

80. Jingzhe, P.: Modelling sintering at different length scales. Int. Mater. Rev. 48(2), 69-85 (2003). https://doi.org/10.1179/ 095066002225010209

81. Kamp, C.J., Zhang, S., Bagi, S., Wong, V., Monahan, G., Sappok, A., Wang, Y.: Ash permeability determination in the diesel particulate filter from ultra-high resolution 3D X-Ray imaging and image-based direct numerical simulations. SAE Int. J Fuels Lubr. 10, 608-618 (2017). https://doi.org/10.4271/2017-01-0927

82. Cooper, J.D., Gladden, L.F., Sederman, A.J., York, A.ndrew.P.E.: Magnetic resonance imaging of the internal and external hydrodynamics in wall-flow particulate filters. In: SAE Technical Paper. SAE International. https://doi.org/10.4271/2019-01-2286 (2019)

Publisher's Note Springer Nature remains neutral with regard to jurisdictional claims in published maps and institutional affiliations. 